\title{
Metal Oxide-Based Photocatalytic Paper: A Green Alternative for Environmental Remediation
}

\author{
Daniela Nunes*(D), Ana Pimentel, Rita Branquinho (D), Elvira Fortunato and Rodrigo Martins *(D) \\ Department of Materials Science, NOVA School of Science and Technology, Campus de Caparica, i3N/CENIMAT, \\ 2829-516 Caparica, Portugal; acgp@campus.fct.unl.pt (A.P.); ritasba@fct.unl.pt (R.B.); emf@fct.unl.pt (E.F.) \\ * Correspondence: daniela.gomes@fct.unl.pt (D.N.); rm@uninova.pt (R.M.); \\ Tel.: +351-212948562 (D.N. \& R.M.); Fax: +351-21-294-8558 (D.N. \& R.M.)
}

\begin{abstract}
The interest in advanced photocatalytic technologies with metal oxide-based nanomaterials has been growing exponentially over the years due to their green and sustainable characteristics. Photocatalysis has been employed in several applications ranging from the degradation of pollutants to water splitting, $\mathrm{CO}_{2}$ and $\mathrm{N}_{2}$ reductions, and microorganism inactivation. However, to maintain its eco-friendly aspect, new solutions must be identified to ensure sustainability. One alternative is creating an enhanced photocatalytic paper by introducing cellulose-based materials to the process. Paper can participate as a substrate for the metal oxides, but it can also form composites or membranes, and it adds a valuable contribution as it is environmentally friendly, low-cost, flexible, recyclable, lightweight, and earth abundant. In term of photocatalysts, the use of metal oxides is widely spread, mostly since these materials display enhanced photocatalytic activities, allied to their chemical stability, non-toxicity, and earth abundance, despite being inexpensive and compatible with low-cost wet-chemical synthesis routes. This manuscript extensively reviews the recent developments of using photocatalytic papers with nanostructured metal oxides for environmental remediation. It focuses on titanium dioxide $\left(\mathrm{TiO}_{2}\right)$ and zinc oxide $(\mathrm{ZnO})$ in the form of nanostructures or thin films. It discusses the main characteristics of metal oxides and correlates them to their photocatalytic activity. The role of cellulose-based materials on the systems' photocatalytic performance is extensively discussed, and the future perspective for photocatalytic papers is highlighted.
\end{abstract}

Keywords: cellulose-based materials; metal oxide nanostructures; photocatalysis; green and sustainable; environmental remediation

\section{Introduction}

This review explores the recent progress concerning the applications of cellulose-based materials in the field of photocatalysis. The main structural characteristics of cellulose and metal oxides as nanostructures or thin films are described. $\mathrm{TiO}_{2}$ and $\mathrm{ZnO}$ are the selected metal oxide photocatalysts. The concept of photocatalytic paper is reviewed, and several studies are presented and discussed.

\subsection{Cellulose-Based Materials}

Cellulose is the most abundant biopolymer on earth, and presents unique characteristics including its biocompatibility and recyclability; it is also lightweight, flexible, foldable, biodegradable, and low cost [1]. This material can be extracted from cotton, wood, hemp, rice, algae, bacteria, and several other sources [1,2]. It is widely employed for producing paper, plastics, textile fabrics, among others.

Cellulose consists of repeating glucose monomers, where the polysaccharide with a molecular structure of $\left(\mathrm{C}_{6} \mathrm{H}_{10} \mathrm{O}_{5}\right)_{\mathrm{n}}$ is linked together through $\beta$-1,4-glycosidic bonds by a condensation reaction $[1,3]$. Each repeating unit contains hydroxyl groups, and their ability to make hydrogen bonds between cellulose chains determines the final cellulose properties and contributes to its high tensile strength $[1,4,5]$. The formation of fibrils is 
resultant from the Van der Waals and intermolecular hydrogen bonds between hydroxyl groups and oxygens of closer molecules that assist the aggregation of several cellulose chains during biosynthesis, resulting, thus, in the fibrils. These fibrils will aggregate and originate microfibrils (5-50 $\mathrm{nm}$ in diameter and several microns in length) [3-5]. The overall microfibril structure can comprehend heterogeneous areas, with areas where the cellulose chains are arranged with high crystalline order and other areas with low order (amorphous) [1,3].

Six cellulose crystalline polymorphs are currently known, namely cellulose I, II, IIII, $\mathrm{III}_{\mathrm{II}}, \mathrm{IV}_{\mathrm{I}}$, and $\mathrm{IV}_{\mathrm{II}}$, in which cellulose I and II are found in nature [4]. Cellulose II is known to be the most thermodynamicallystable structure, with cellulose I (metastable) converting to II or III [3]. Each polymorph of crystalline cellulose has been systematically investigated and their structure and characteristics are well documented [3,5], so this will not be further covered in this work.

Traditional paper, with cellulose fibers of about $20 \mu \mathrm{m}$ in diameter, is usually rough (roughness of hundreds of micrometers) [1]. However, cellulose can reach the nanometer size by means of a disintegration process of the micrometer-sized cellulose fibers. Some examples are microfibrillated cellulose (MFC), nanofibrillated cellulose (NFC), and nanocrystalline cellulose (NCC), which are produced with different disintegration processes $[1,6,7]$. The transparent NCC membrane (Figure 1) is composed of well-organized three-dimensional structures, with long entangled filaments of a cellulose microfibril network. The average width of the cellulose fibers is within 20-50 nm [7]. Another type of nanocellulose is bacterial nanocellulose (BNC). The bacterium Gluconacetobacter is normally responsible for the production of BNC membranes (Figure 1), and such a nanomaterial presents enhanced chemical purity, high crystallinity, and low surface roughness and porosity [8]. As expected, the purified cellulose materials have improved intrinsic properties, including a higher Young's modulus and lower thermal expansion coefficient, among others [1]. The purified BNC membranes are also transparent, which allows their integration in several applications that require this specification.
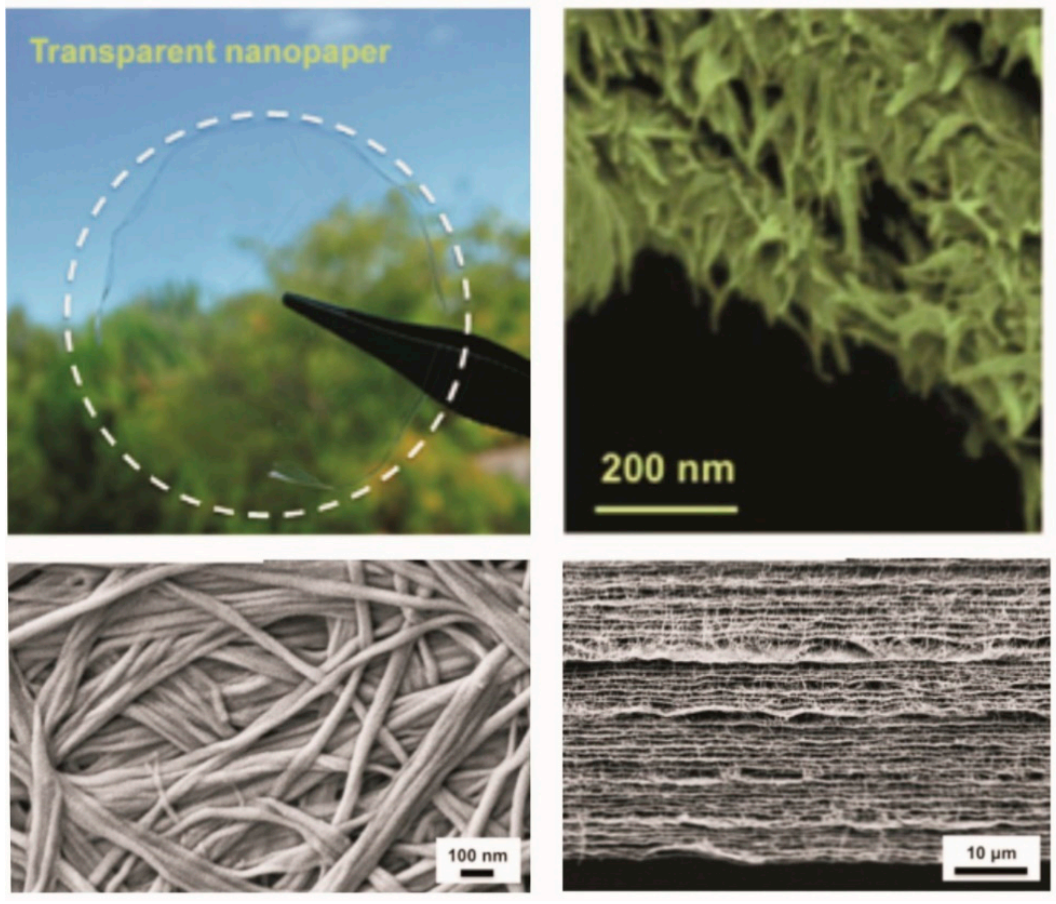

Figure 1. Photograph of nanocrystalline cellulose membrane and corresponding scanning electron microscopy (SEM) micrograph. The SEM image of the bacterial cellulose surface (bottom images) obtained from the direct drying process and corresponding cross-section. Reproduced with permission of Elsevier [7]. 
Cellulose-based materials have been employed in distinct applications, including optoelectronic devices, such as solar cells and transistors [7,9,10], sensors [11-14], electrochromic devices $[15,16]$, but also in diagnostic platforms $[17,18]$ and photocatalysis $[12,19,20]$. In terms of photocatalysis, despite all the envisioned applications of paper-based materials, its implementation is not straightforward.

\subsection{Photocatalytic Paper}

Extensive efforts have been made by the scientific community and developed countries to promote renewable or carbon-neutral energy sources and find solutions for diminishing the ever-growing industrial residues and human contaminants. Photocatalysis can be considered an appealing strategy to diminish these problems, especially in terms of water purification, with major advantages over the most common methods used, including room temperature reactions, low secondary pollutants' generation and minimal operation costs [21]. Moreover, the photocatalytic process fits in the Sustainable Development Goals by the UN for research and innovation, especially Goal 6, focused in Clean Water and Sanitation [22]. This ever-growing investigation field is reported to have started in 1972, with Fujishima and Honda [23] demonstrating the use of $\mathrm{TiO}_{2}$ for the photoelectrochemical splitting of water using UV light, and further photogeneration of charge carriers in $\mathrm{TiO}_{2}$ [24].

Photocatalysis can be understood as the change of a chemical reaction's rate caused by a photocatalyst (metal oxide material) in the presence of a light source, i.e., ultraviolet (UV), visible (VIS), mixture of both UV+VIS, and solar radiation. There are two types of photocatalytic reactions, i.e., homogeneous and heterogeneous photocatalysis. In homogeneous catalysis, the reactant and catalyst are in the same phase, while in heterogeneous catalysis, both reaction participants are in distinct phases [25]. This process involves excitation, diffusion, and photo-induced charge carriers. A hole-trapping mechanism based on the adsorption/desorption of chemisorbed oxygen molecules at the semiconductor surface governs the photocatalytic process. When the semiconductor is exposed to a light source higher than its band gap $\left(\lambda<388 \mathrm{~nm}\right.$ for $\mathrm{TiO}_{2}$ [26] and $\sim 370 \mathrm{~nm}$ for $\mathrm{ZnO}$ [27]), electronhole pairs are generated (electrons are generated $\left(\mathrm{e}_{\mathrm{CB}}{ }^{-}\right)$in the conduction band, while holes $\left(\mathrm{h}_{\mathrm{VB}}{ }^{+}\right)$, in the valence band), in which these photo-generated holes and electrons diffuse to the surface, oxidizing and reducing oxygen and water molecules. With that, reactive radicals $\left(\mathrm{O}_{2}{ }^{\bullet-}\right.$ and $\left.\mathrm{OH}^{\bullet}\right)$ are created (Figure 2), and such radicals will decompose organic and inorganic compounds on the semiconductor's surface (Figure 2) $[25,28,29]$. The photocatalytic process will mineralize the organic pollutants into carbon dioxide $\left(\mathrm{CO}_{2}\right)$, water $\left(\mathrm{H}_{2} \mathrm{O}\right)$ and mineral acids in the presence of the semiconductor photocatalyst and reactive oxidizing species [30]. In brief, the relevant reactions of the organic compounds' photodegradation in the presence of a metal oxide semiconductor are summarized as follows [30-32]:

$$
\begin{gathered}
\text { Semicondutor }+\mathrm{hv} \rightarrow \mathrm{e}_{\mathrm{CB}}^{-}+\mathrm{h}_{\mathrm{VB}}^{+} \\
\mathrm{H}_{2} \mathrm{O}+\mathrm{h}_{\mathrm{VB}^{+}} \rightarrow \mathrm{H}^{+}+\mathrm{OH}^{\bullet} \\
\mathrm{O}_{2}+\mathrm{e}_{\mathrm{CB}}{ }^{-} \rightarrow \mathrm{O}_{2}{ }^{-} \\
\mathrm{O}_{2}^{\bullet-}+\mathrm{H}^{+} \rightarrow \mathrm{HO}_{2}{ }^{\bullet} \\
\mathrm{HO}_{2}{ }^{\bullet}+\mathrm{HO}_{2}^{\bullet} \rightarrow \mathrm{H}_{2} \mathrm{O}_{2}+\mathrm{O}_{2} \\
\mathrm{H}_{2} \mathrm{O}_{2}+\mathrm{e}_{\mathrm{CB}^{-}} \rightarrow \mathrm{OH}^{-}+\mathrm{OH}^{\bullet} \\
\mathrm{H}_{2} \mathrm{O}_{2}+\mathrm{O}_{2}^{\bullet-} \rightarrow \mathrm{OH}^{\bullet}+\mathrm{OH}^{-}+\mathrm{O}_{2} \\
\mathrm{H}_{2} \mathrm{O}_{2}+\mathrm{hv} \rightarrow 2 \mathrm{OH}^{\bullet} \\
\text { Organic compounds }+\mathrm{OH}^{\bullet} \rightarrow \text { Intermediates } \rightarrow \mathrm{CO}_{2}+\mathrm{H}_{2} \mathrm{O}
\end{gathered}
$$

Photocatalysis has been reported to decompose organic compounds, such as alcohols, carboxylic acids, phenolic derivatives, and aromatic amines and halides, among others [33]. 
Nevertheless, most photocatalytic studies focus on the degradation of organic pollutants using organic model dyes that simulate pollutants released by industries, textile, pulp and paper, and several other industrial activities, directly to the environment. These organic dyes are complex molecules used to color textiles or products. They are water-soluble, with some being toxic and causing severe impacts on human health [34]. Moreover, these contaminants have a catastrophic effect on the environment and animals, interfering with the reoxygenation capacity of water bodies and blocking sunlight that will directly influence photosynthesis processes [35]. Rhodamine B, methylene blue, methyl orange, congo red, and other azo dyes are examples of model dyes tested in photocatalysis studies [19,35-39]. In terms of inorganic species, bromate, chlorate, halide ions, nitric oxide, palladium, rhodium and sulfur species can be decomposed by photocatalysis, but also metal salts and organometallic compounds [33].

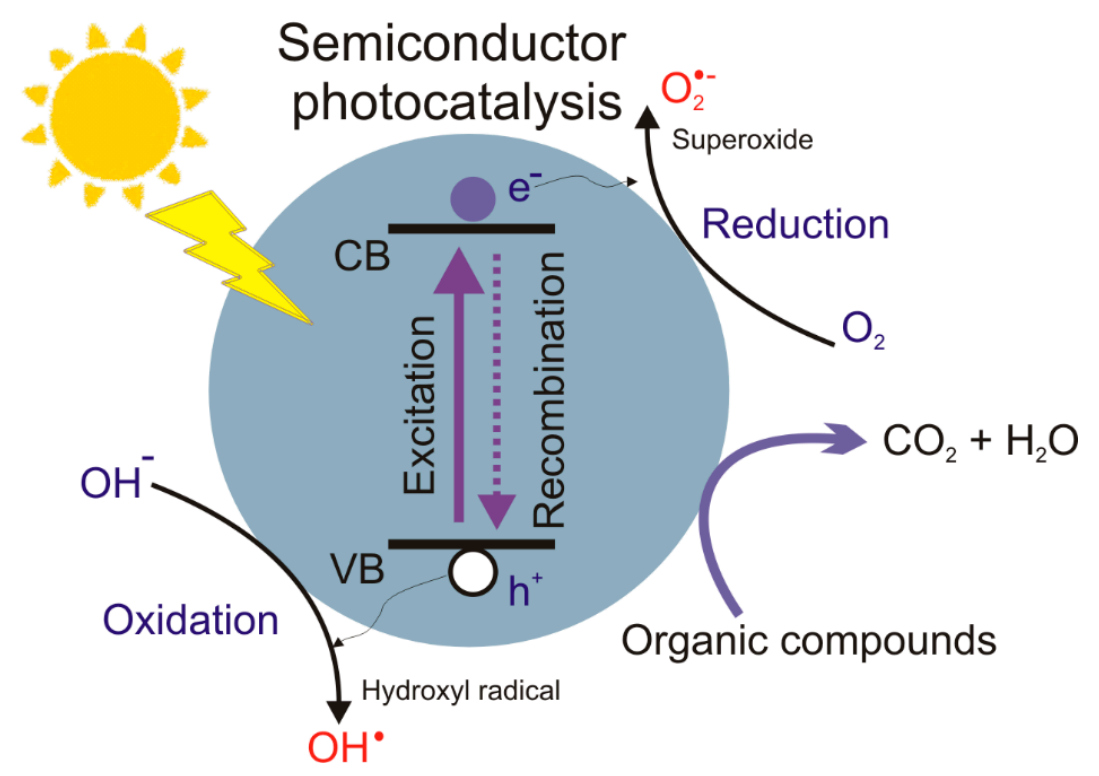

Figure 2. Mechanism of semiconductor photocatalysis. Adapted from [40].

The photocatalyst plays a key role in the whole process. The use of nanoparticles in photocatalysis has been largely reported [41-47]; however, the use of nano-photocatalysts in the powder form presents some limitations, especially when it comes to their recovery. The most commonly used commercial $\mathrm{TiO}_{2}$ photocatalyst is also included, with sizes of $\sim 30 \mathrm{~nm}$ [48]. Moreover, during the repeated photocatalytic processes, the loss of photocatalysts is highly expected [49]. One way to overcome these limitations is to use membranes, thin films or nanostructures grown/deposited on substrates. In fact, the substrate used, it can contribute to the final photocatalytic activity of the system. Several studies reported photocatalysts grown or deposited on rigid substrates [38,50-52]; however, nowadays the search for flexible substrates is tremendous as these substrates can easily adapt to curved/rough surfaces and decrease production costs. Nanostructures grown on polyethylene terephthalate (PET) [37] or polyethylene naphthalate (PEN) [36], and cotton fabric substrates [53], among others, have been previously reported for photocatalytic applications. Photocatalytic papers have also been previously reported [20,54-56], in which the greater advantage of using paper as a substrate is related to its porous structure that can assist the photodegradation target to diffuse in and the reactive oxygen to migrate out [57]. Moreover, taking advantage of the pore structure created by a reticular fiber network, it has been previously reported that paper was employed as an enhanced support material for gas phase catalytic reactions [55]. Photocatalytic paper is not considered a disposable product anymore, as it can be reutilized several times for the degradation of organic modeling dyes [58]. 
The main research efforts in photocatalysis are related to materials design and the development of photoreactive systems. The former includes the integration of cellulose-based materials to the photocatalytic system and, in the case of the metal oxide photocatalysts, the search for enhanced nanostructures or thin films for increasing photocatalytic performance.

\subsection{Metal Oxide Nanostructures and Thin Films}

Metal oxides are a class of materials that have been largely investigated over the years due to their unique properties. These materials are known as being highly stable, in some cases, biocompatible, low cost and environmentally friendly, despite their exceptional ability to generate charge carriers under light irradiation [59] with enhanced electrical and optical characteristics and high optical transparency [11,37,38,60-64]. Moreover, at the nanoscale level, these materials can present high surface-to-volume ratios, high surface reaction activity, high catalytic efficiency, and strong adsorption ability [65].

Metal oxides can exhibit different electronic properties, from conducting to semiconducting but also insulating [66]. These materials are known to have the s-shells of positive metallic ions always fully filled by electrons, but the d-shells may not be totally filled [13,67]. This is responsible for the distinct properties of this source of materials, including the wide band gaps that dictate the final photocatalytic behavior of the system. In fact, metal oxides with wide band gaps are active under UV light. However, the solar UV radiation that reaches the earth's surface is relatively small (3-5\%) [68], making the use of such materials extremely limited for pollutant degradation with UV radiation. Consequently, solutions to make these materials photoactive under the complete solar spectrum, such as band gap engineering, doping or surface modification, are highly desired [69].

These materials can be divided in two groups: non-transition and transition metal oxides. The non-transition ones include the pre- and post-transition metal oxides. The small energy difference between a cation $\mathrm{d}^{\mathrm{n}}$ and either a $\mathrm{d}^{\mathrm{n}+1}$ or $\mathrm{d}^{\mathrm{n}-1}$ configuration is responsible for the differences in the material's behavior. Metal oxides with $\mathrm{d}^{0}$ and $\mathrm{d}^{10}$ electronic configurations present stable properties, while the pre-transition-metal oxides can be inert in several applications due to their large band gaps, so electrons and holes are hardly formed $[13,70]$. $\mathrm{TiO}_{2}, \mathrm{WO}_{3}$ and $\mathrm{V}_{2} \mathrm{O}_{5}$ are in the transition-metal oxide class of materials with $\mathrm{d}_{0}$ configuration, and $\mathrm{ZnO}$ and $\mathrm{SnO}_{2}$ are post-transition metal oxides with $\mathrm{d}_{10}$ configuration [70].

Several studies reported the use of metal oxide materials in the photocatalytic degradation of organic contaminants/dyes [19,34,37,38,71-74]. However, their photocatalytic performance strongly depends on the crystal structure, morphology, elemental composition, crystalline phase, exposed surface facets, intrinsic defects (such as oxygen vacancies), lattice distortions, and doping, among others [75-77]. In fact, the presence of oxygen vacancies directly influences the final photocatalytic performance of such materials [78]. Thus, it is of great importance to design and control crystallinity, shape and size, which will directly influence the charge carriers' separation and final photocatalytic activity [24]. Moreover, it is largely known that materials' properties are enhanced at the nanoscale level when compared to bulk counterparts [79]. For that reason, the surface-to-volume ratio of metal oxides is highly increased at the nanoscale, and more active sites on their surface are available for organic molecules to interact, leading to higher overall adsorption capacity and enhanced photocatalytic performance in environmental remediation $[35,74]$.

Zero-dimension (0D) nanomaterials are known to have high specific surface area, while one-dimensional (1D) nanomaterials may result in less recombination due to the short distance for charge carrier diffusion. Two-dimensional (2D) nanomaterials display large surface-to-volume ratios and materials with three-dimension (3D) have higher carrier mobility and abundant active sites, a consequence of porosity and the channels forming its structure $[80,81]$.

Several techniques have been reported to produce metal oxide nanostructures or thin films, including chemical bath deposition [82,83], the sol-gel method [84], electrospinning [83,85], electrodeposition [86,87], magnetron sputtering [88-90], laser assisted 
flow deposition (LAFD) [91,92], spray pyrolysis [93,94], and hydrothermal/solvothermal synthesis, either by conventional or by microwave assisted heating [36,62,95-99], and several other methods have been employed. With such a variety of production methods reported, several different nanostructures were described, including nanowires, nanorods, nanofibers, nanotubes, nanobelts, nanowhiskers, nanospheres, tetrapods, nanosheets, and many others $[13,71,100-105]$. The 1D nanostructures, which include the nanofibers, nanotubes, nanobelts, nanowhiskers, nanorods and nanowires, are extensively investigated for photocatalysis due to their slower electron-hole recombination resulting in higher photocatalytic oxidation rates. Moreover, these 1D materials have a long axis for the efficient absorption of incident sunlight, and short path lengths for the diffusion of charge carriers $[103,106]$. These nanostructures have been employed in applications beyond photocatalysis, ranging from solar cells $[93,99,107]$ to sensors [108-113], but also in lithium-ion batteries [114-117], fuel cells [71] and so on.

\section{Metal Oxide Photocatalytic Papers}

$\mathrm{TiO}_{2}$ is the most investigated metal oxide photocatalyst [81]; however, the use of other metal oxides in photocatalysis, such as $\mathrm{ZnO}$, has been growing lately $[30,31,118]$. At the nanoscale, these materials can assume several structures, with direct influence on their photocatalytic activity. Moreover, the integration of such nanostructures in substrates is also challenging, including for cellulose-based substrates. The search for photocatalysts capable of performing the degradation of pollutants without the requirement of powder recovery gives visibility to the photocatalytic paper concept. In fact, the paper intrinsic structure can contribute to the photocatalytic degradation process with the possibility of being re-used over the time.

\section{1. $\mathrm{TiO}_{2}$ Photocatalytic Paper}

Titanium dioxide has been largely investigated as a photocatalyst due to its strong oxidizing abilities for the decomposition of organic pollutants, and also its chemical and physical stabilities, nontoxicity, low cost, superhydrophilicity, and earth abundance $[13,69,71,81]$. $\mathrm{TiO}_{2}$ occurs in nature, presenting three crystalline phases: two tetragonal phases, i.e., anatase and rutile, and an orthorhombic phase, i.e., brookite (Figure 3) [119]. However, it also occurs in an amorphous form. Anatase and brookite are both metastable phases that, when heated, transform into rutile, the most stable phase $[120,121]$. The lattice parameters of anatase $\left(I 4_{1} /\right.$ amd $)$ are $a=0.3785 \mathrm{~nm}$ and $c=0.9515 \mathrm{~nm}$, for rutile $\left(\mathrm{P}_{2} / \mathrm{mnm}\right)$ are $a=0.4594 \mathrm{~nm}$ and $c=0.2958 \mathrm{~nm}$, while brookite $(\mathrm{Pbca})$ has lattice parameters of $a=0.9184 \mathrm{~nm}, b=0.5447 \mathrm{~nm}$, and $c=0.5145 \mathrm{~nm}[122,123]$. The three crystalline phases have $\mathrm{TiO}_{6}$ octahedra with different distortions, in which the structural and electronic properties of all the phases can be determined by the Ti-O bonds. The description of the $\mathrm{TiO}_{2}$ structure and stoichiometry is well documented elsewhere $[13,71,122,124]$, so this will not be covered here.
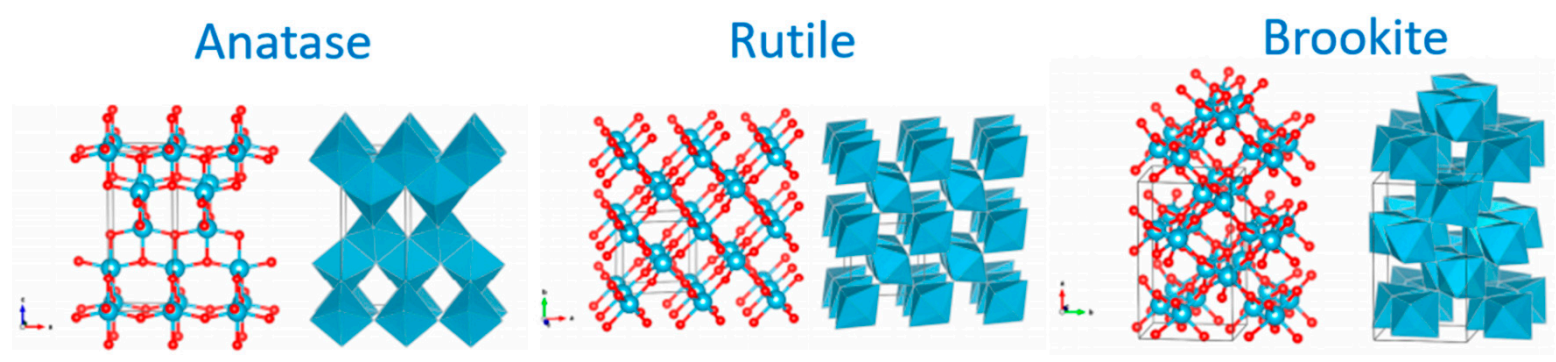

Figure 3. Unit cells of $\mathrm{TiO}_{2}$ rutile, anatase and brookite [125]. Reprinted with permission from Structural Characteristics and Mechanical and Thermodynamic Properties of Nanocrystalline $\mathrm{TiO}_{2}$, Chemical Reviews, 2014, 114, 19, 9613-9644. Copyright 2021 American Chemical Society. 
$\mathrm{TiO}_{2}$ is a $n$-type semiconductor material with a wide energy band gap, displaying optical band gaps of 3.0 and $3.2 \mathrm{eV}$ for rutile and anatase, respectively [126]. The band gap values of brookite vary in the literature and have been reported to be from 3.13 to $3.40 \mathrm{eV}[120,126]$. With the large band gap of all $\mathrm{TiO}_{2}$ phases, the solar radiation absorption is limited to the UV range, which restricts its widely photocatalytic application for environmental remediation. Other restrictions to the extensive use of $\mathrm{TiO}_{2}$ in photocatalysis are related to the rapid recombination of the photogenerated electron-hole pairs and poor affinity towards hydrophobic organic pollutants [69].

$\mathrm{TiO}_{2}$ is usually used as a photocatalyst in the forms of anatase, generally with higher photocatalytic activity, and rutile, which is less photoactive [48,69,127-130]. The enhanced photocatalytic performance of anatase can be related to three main reasons: (i) its larger band gap when compared to rutile, which raises the valence band maximum to higher energy levels relative to redox potentials of adsorbed molecules, thus influencing the oxidation of electrons and facilitating electron transfer from $\mathrm{TiO}_{2}$ to adsorbed molecules; (ii) its indirect bandgap that exhibits a longer lifetime of photoexcited electrons and holes when compared to the direct bandgap of rutile and brookite [129]; and (iii) the concentration of oxygen vacancies is higher for anatase nanomaterials, which leads to a greater charge separation efficiency [121]. In the case of brookite, the interest on its photocatalytic activity has been growing lately $[120,131,132]$, which has been reported to have higher photocatalytic activity than anatase or rutile [133]. The determination of the best photocatalyst among the three $\mathrm{TiO}_{2}$ phases is still under intense debate. Moreover, it has been shown that the mixture of the $\mathrm{TiO}_{2}$ phases displays higher photocatalytic activity than the pure phases [37,134], reducing the recombination of photogenerated holes and electrons [135]. In fact, the most common commercial photocatalyst is Degussa P-25, that consists of both rutile and anatase phases [130].

The higher photocatalytic activity in terms of exposed active facets was reported as $\{111\}>\{001\}>\{100\}>\{101\}$ for anatase [136], $\{110\}>\{001\}>\{100\}$ for rutile [129] and $\{210\}$ for brookite [120]. The active facets have a direct effect on the surface adsorption or desorption abilities and the redox potential of the charge carriers, such as the surface area, with more active sites for reaction on the nanomaterials' surface [137].

To overcome the limitations involving the use of $\mathrm{TiO}_{2}$ in photocatalysis under solar radiation, several approaches have been reported. One possibility involved the engineering of the $\mathrm{TiO}_{2}$ optical bang gap by adding oxygen vacancies or doping with non-metal and metal elements to narrow its band gap [138-140]. It has been reported that oxygen vacancies facilitate the charge separation process [141], while doping with external elements can increase the redox potential of the radicals and increase quantum efficiency by reducing the degree of recombination of the electrons and holes, despite enlarging the $\mathrm{TiO}_{2}$ absorption spectrum [142]. Surface modification, fabrication of composites or heterojunctions with other metal oxides or other materials such as graphene have also been reported to expand $\mathrm{TiO}_{2}$ photocatalytic activity under solar radiation [69,143-147]. Lately, several reviews describing the $\mathrm{TiO}_{2}$ band gap reduction to the visible region and further photocatalytic activity under visible/solar radiation have been conducted, demonstrating the use of different materials and several methods that were investigated [143,147-150].

$\mathrm{TiO}_{2}$ is a very versatile material and to satisfy the most distinct applications of this material, different structures have been designed and produced. In terms of nanomaterials, $\mathrm{TiO}_{2}$ nanowires, nanorods, nanofibers, nanotubes, nanobelts, nanowhiskers, nanospheres, and nanoflowers, among others, have been described (Figure 4) [36-38,151-156]. $\mathrm{TiO}_{2}$ thin films have been also largely investigated [157-159]. Various techniques have been reported for producing $\mathrm{TiO}_{2}$ nanostructures or thin films including wet-chemical techniques $[160,161]$, the sol-gel method [84,158], thermal evaporation [162], magnetron sputtering $[163,164]$, anodization $[165,166]$, electrodeposition $[167,168]$, the gas jet fiber spinning process [103], electrospinning [104,169], hydrothermal and solvothermal synthesis [170-173], and microwave irradiation $[15,36,38]$, among several other methods. 

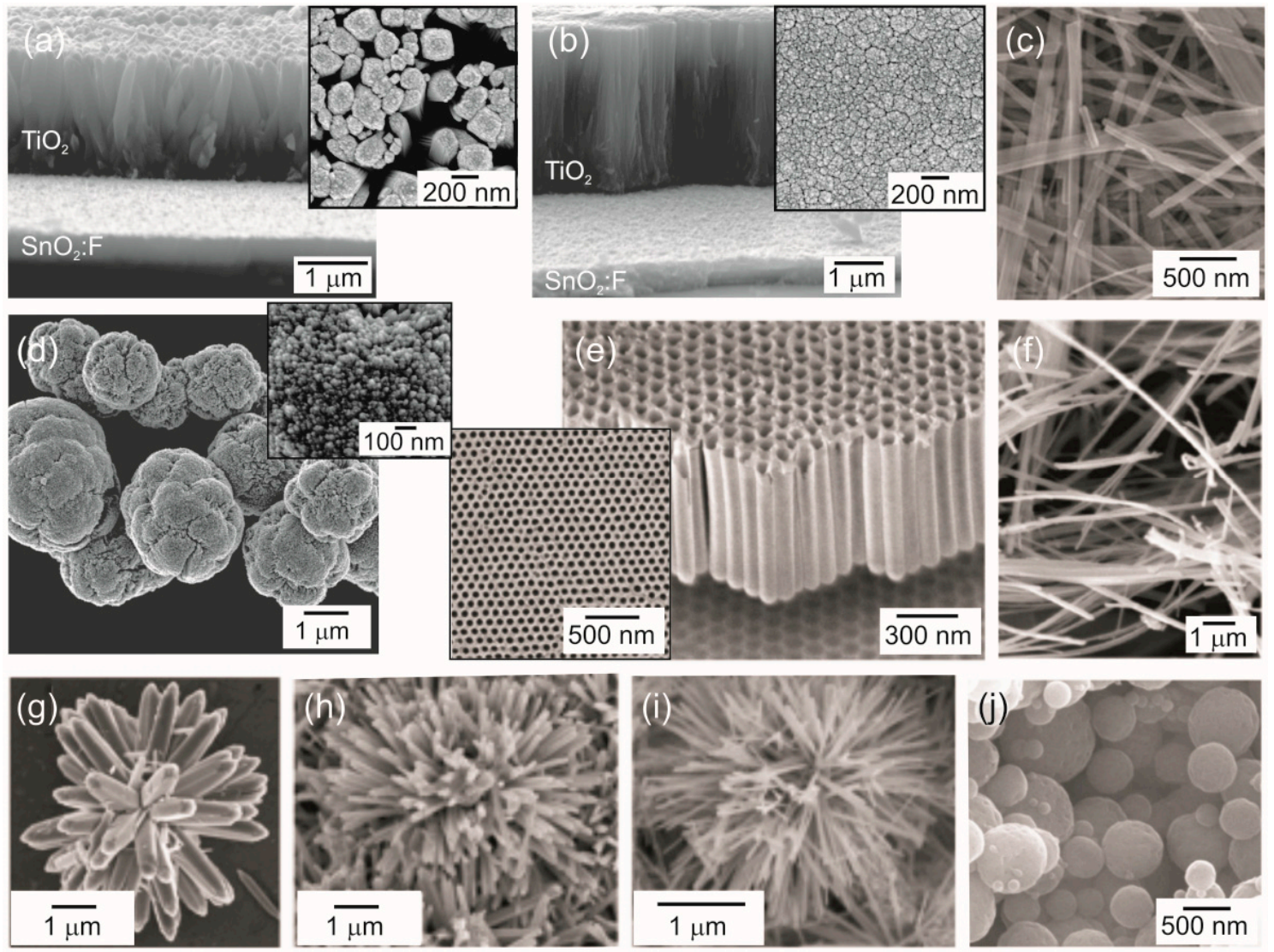

Figure 4. SEM images of several $\mathrm{TiO}_{2}$ nanostructures. (a,b) $\mathrm{TiO}_{2}$ nanorods grown of a $\mathrm{SnO}_{2}: \mathrm{F}$ seed layers [38], (c) $\mathrm{TiO} 2$ nanobelts [174], (d) $\mathrm{TiO}_{2}$ nanorods aggregated to form micro-sized spheres [37], (e) $\mathrm{TiO}_{2}$ nanotubes formed by anodization [175], (f) $\mathrm{TiO}_{2}$ nanowires [176], (g-i) different types of $\mathrm{TiO}_{2}$ nanoflowers [155], and (j) $\mathrm{TiO}_{2}$ nanospheres [156]. Reproduced with permission of Elsevier [38,156,174-176], MDPI [37] and Springer Nature [155].

The integration of $\mathrm{TiO}_{2}$ in cellulose-based materials to form composites or membranes has been reported, but the growth or deposition of thin films or nanostructures on a paper substrate has also shown promise $[12,15,19,177,178]$. Hu et al. [179] produced a flexible and binder-free graphene- $\mathrm{TiO}_{2}$ paper to be applied as lithium-ion battery anode materials, consisting of 3-D nano-structures with nano-sized $\mathrm{TiO}_{2}$ intercalated between graphene layers as pillars to increase the Li-ion insertion/extraction rate. In [15], electrochromic $\mathrm{TiO}_{2}$ nanostructured films were grown on gold coated papers using a microwave-assisted hydrothermal method at a low synthesis temperature to produce electrochromic (EC) devices. The effect of the acid used in the microwave synthesis played a crucial role on the film's structure and final EC performance (Figure 5).

Several studies described the photocatalytic activity of $\mathrm{TiO}_{2}$ paper-based photocatalysts with gaseous or liquid pollutants. In 1995, Matsubara et al. [180] reported the production of a $\mathrm{TiO}_{2}$-containing paper and investigated its photocatalytic activity by measuring the decomposition of gaseous acetaldehyde under a weak UV light irradiation. Iguchi et al. [181] prepared photocatalytic papers containing $\mathrm{TiO}_{2}$ supported on inorganic fibers. The photodegradation performance of acetaldehyde gas and the durability of the $\mathrm{TiO}_{2}$-containing papers have been investigated under UV irradiation. In [182], photocatalytic papers fabricated with nano $\mathrm{TiO}_{2}$ powders doped with nitrogen and iron and supported on $\mathrm{X}$ zeolite were tested for the photodegradation of acetaldehyde in air, as an indoor pollutant under visible light irradiation (batch conditions). 

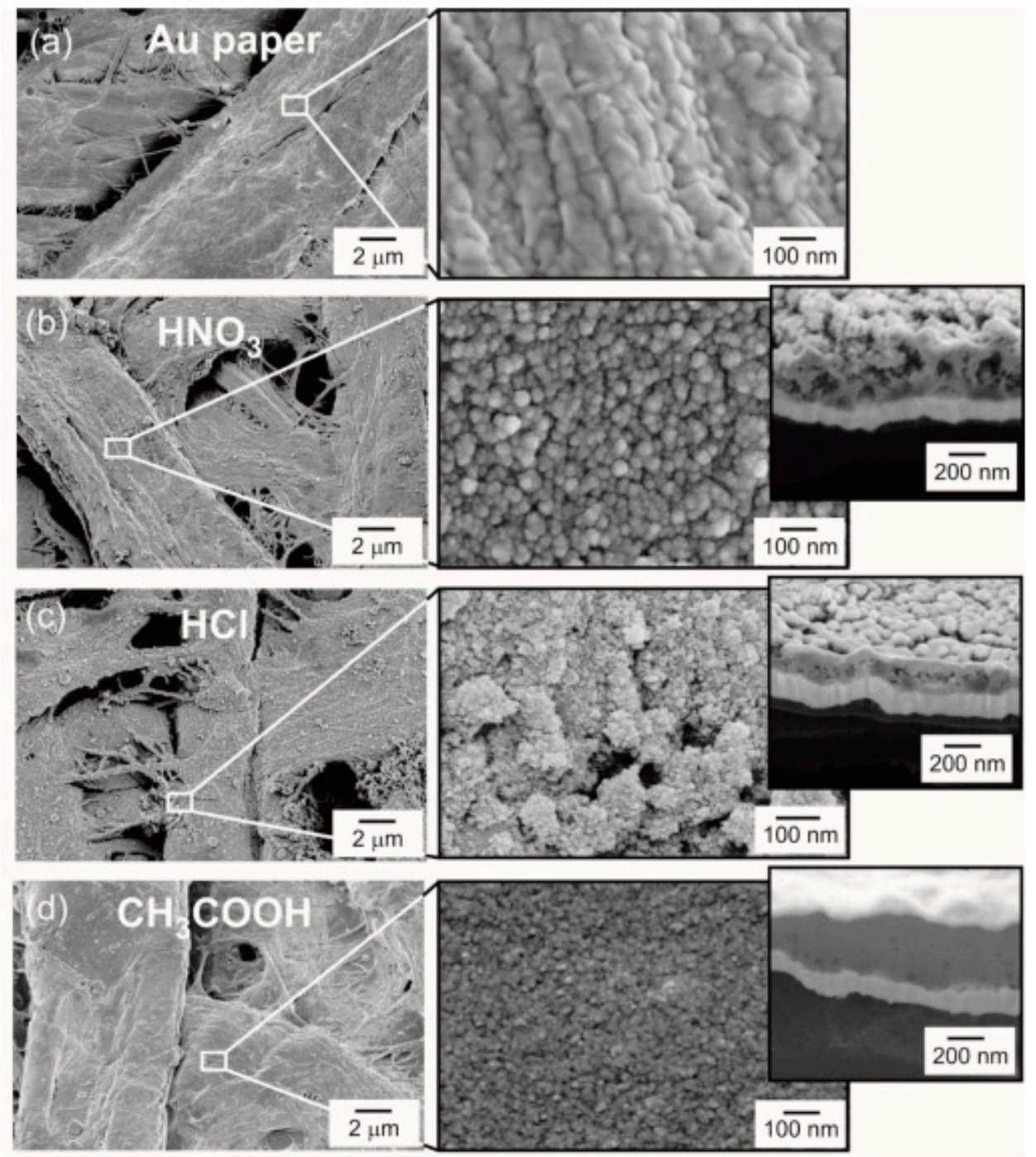

Figure 5. SEM images of the Whatman paper with an $\mathrm{Au}$ film and the $\mathrm{TiO}_{2}$ nanostructured films grown under microwave irradiation to be used as EC devices. Magnified SEM image of the Au film in (a) and magnified and cross-section SEM images of the $\mathrm{TiO}_{2}$ nanostructured films produced with (b) nitric acid; (c) hydrochloric acid; and (d) acetic acid [15]. Reproduced with permission of MDPI [15].

Sboui et al. [183] reported the functionalization of papers with $\mathrm{TiO}_{2}$ decorated with $\mathrm{AgBr}$ nanoparticles. Their photocatalytic performance was evaluated through the degradation of 2-propanol in gas phase under sunlight exposure. In another approach, the fabrication of photocatalytic paper using $\mathrm{TiO}_{2}$ nanoparticles confined in hollow silica capsules has been shown (Figure 6) [55]. The encapsulation demonstrated a shielding effect that can insulate the $\mathrm{TiO}_{2}$ nanoparticles from the surrounding environment and prevent the self-degradation of organic support materials under UV light. The encapsulated $\mathrm{TiO}_{2}$ nanoparticles have been deposited onto the cellulose paper either by a chemical adhesion process via ionic bonding or by a physical adhesion process using a dual polymer system. The photocatalytic activity was assessed with 2-propanol degradation under UV-light exposure. 


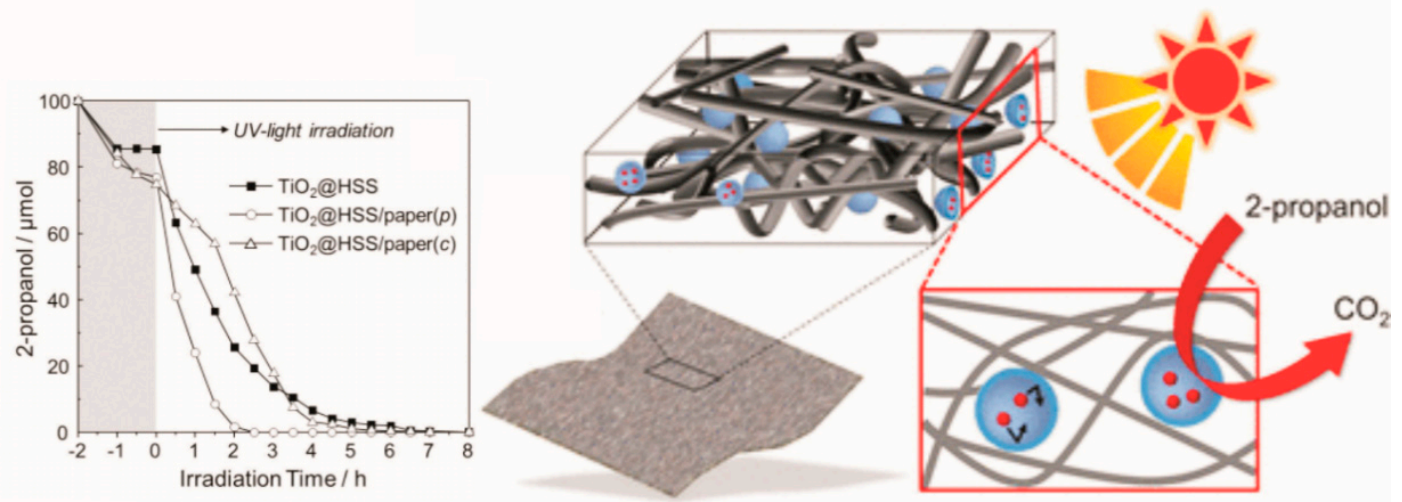

Photocatalytic paper composite
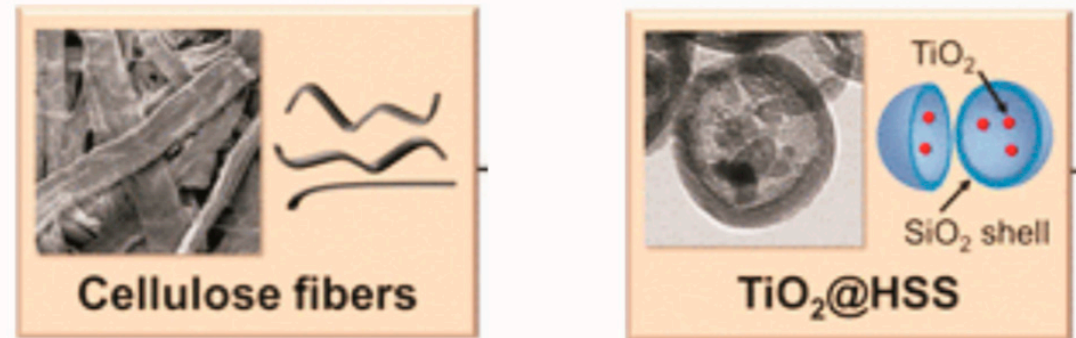

Figure 6. Photocatalytic degradation of 2-propanol and SEM images of paper fibers and the $\mathrm{TiO}_{2}$ nanoparticles confined in hollow silica capsules (HSS) [55]. Reprinted with permission from fabrication of photocatalytic paper using $\mathrm{TiO}_{2}$ nanoparticles confined in hollow silica capsules, Langmuir 2017, 33, 1, 288-295. Copyright 2021 American Chemical Society.

Zhang et al. [57] reported a cellulose-based photocatalytic material with $\mathrm{TiO}_{2}$ nanoparticles loaded on carbon fibers. $\mathrm{Na}_{2} \mathrm{SiO}_{3}$ or $\mathrm{Al}_{2}\left(\mathrm{SO}_{4}\right)_{3}$ were used as adhesives, with differences in the photodegradation behaviors of methyl orange (MO) depending on the composite used. The ratio of carbon/cellulose fibers also demonstrated to influence the MO photodegradation. Qin et al. [58] described the production of photocatalytic papers containing a mixture of poly-dopamine-loaded cellulose fibers and pristine cellulose fibers and $\mathrm{TiO}_{2}$ nanoparticles. The photocatalytic performance of $\mathrm{TiO}_{2}$ photocatalytic paper was shown by decomposing methyl orange under UV light irradiation. In [184], $\mathrm{TiO}_{2}$-coated non-woven paper was tested as a photocatalyst for the degradation of Rhodamine $\mathrm{B}$ in aqueous solutions. $\mathrm{TiO}_{2}$ was coated on non-woven paper using an aqueous dispersion of colloidal $\mathrm{SiO}_{2}$ binder. The photodegradation was temperature-dependent with a high degradation rate being achieved at high temperature. Moreover, the presence of $\mathrm{Cl}^{-}$, $\mathrm{CH}_{3} \mathrm{COO}^{-}$and $\mathrm{HPO}_{4}{ }^{2-}$ ions led to the reduction of the photodegradation rate, while the presence of $\mathrm{SO}_{4}{ }^{2-}$ increased it. The binder assists the adhesion of $\mathrm{TiO}_{2}$ on paper fibers and prevents the degradation of paper imposed by the oxidation effect of $\mathrm{TiO}_{2}$ [185]. Jiao et al. [186] showed anatase $\mathrm{TiO}_{2}$ on paper and this photocatalyst degraded blue indigo carmine dye under UV radiation. Toro et al. [187] reported the fabrication of $\mathrm{TiO}_{2}$ hydrosols on paper sheets and their photocatalytic behavior was investigated under UV radiation using methylene blue as a model dye.

Photocatalytic papers based on a $\mathrm{TiO}_{2} /$ Sodium alginate nanocomposite were reported in [185] (Figure $7 \mathrm{a}-\mathrm{c}$ ). Their photocatalytic activity was investigated with the removal of chemical oxygen demand of wastewater. The increase in the photocatalyst increased the wastewater mineralization and enhanced the removal of chemical oxygen demand, as expected (Figure 7d). It has been shown that the presence of sodium alginate as a biopolymer increased the adhesion of nanoparticles to paper fibers and reduced the harmful effect imposed by the photocatalyst. 

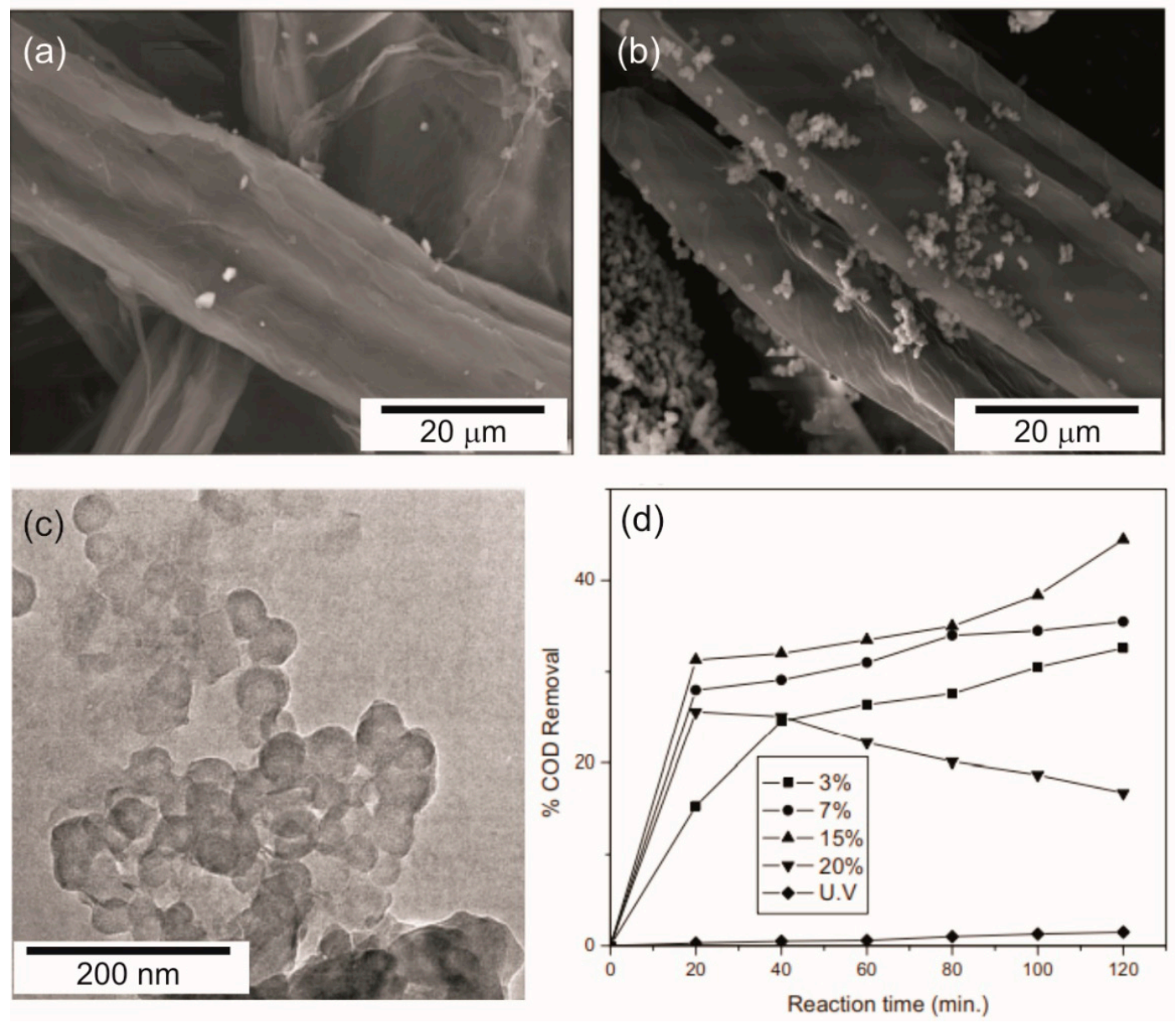

Figure 7. (a) SEM images of the photocatalytic paper containing $7 \%$ and (b) $20 \%$ of $\mathrm{TiO}_{2} /$ Sodium alginate nanocomposite, and (c) transmission electron microscopy (TEM) images of the nanocomposite. (d) Photocatalytic degradation for the removal of chemical oxygen demand of wastewater. Reproduced with permission of Elsevier [185].

A paper- $\mathrm{TiO}_{2}$ composite was developed in [178] and the efficiency of the resulting photocatalyst was investigated by degradation of gaseous 2-propanol under simulated sunlight irradiation. Another study reported a ternary composite composed by Au nanoparticles decorating $\mathrm{TiO}_{2}$ nanowires onto hierarchically porous carbon fiber paper. Its photocatalytic activity was investigated with the degradation of gaseous styrene under visible light irradiation [177].

Two analogous studies reported the production of photocatalytic papers composed by nanosized $\mathrm{TiO}_{2}$ supported on natural zeolite $[188,189]$. The fibers formed a closely packed network with microvoids, with the zeolite-based $\mathrm{TiO}_{2}$ particles being randomly attached to these fibers. The natural zeolite-based $\mathrm{TiO}_{2}$ composite sheets decomposed gaseous toluene under UV radiation, and the photocatalytic efficiency was attributed to the synergy effect with (1) confinement of the organic contaminant in the microvoids between the fiber networks, (2) its further adsorption on zeolite and (3) the subsequent photodecomposition of adsorbate by $\mathrm{TiO}_{2}$ nanoparticles [188]. In [190], a photocatalytic paper formed by a composite of $\mathrm{TiO}_{2} / \mathrm{SiO}_{2}$ particles introduced in bulk paper had its activity demonstrated by the degradation of ethanol (50-200 ppm) under UV irradiation.

A review on the topic was published in 2006, where Pelton et al. [56] revised the photocatalytic paper developments at that time, which included methods to fix $\mathrm{TiO}_{2}$ on cellulose substrates to minimize photochemical damage to the paper; moreover, the use of multiple approaches for enhancing mineralization were discussed for better photocatalytic disinfection. 
When it comes to growing $\mathrm{TiO}_{2}$ nanostructured films on paper, where paper is the substrate, D. Nunes et al. [19] reported the synthesis of $\mathrm{TiO}_{2}$ nanostructured films using microwave irradiation at low temperature synthesis $\left(80^{\circ} \mathrm{C}\right)$ and without any seed layer, in which bacterial nanocellulose and tracing paper were tested as substrates (Figure 8a-d). Their photocatalytic activity was investigated using Rhodamine B degradation under solar radiation. The nanocellulose based material demonstrated higher photocatalytic activity than tracing paper, in which the structural differences of the $\mathrm{TiO}_{2}$ nanostructured films and substrates play a key role on the behavior observed (Figure 8e,f). It has been reported that a nanocellulose substrate with a 3D structure at the nanoscale can effectively enhance photocatalytic activity. Moreover, the 3D closed packed cellulose nanofiber network of nanocellulose fully covered with $\mathrm{TiO}_{2}$ provides more active sites for the photoreaction, and also facilitates the species' transport and electrons' collection [191]. The BNC-based material could be reutilized despite activity deterioration over the exposures.
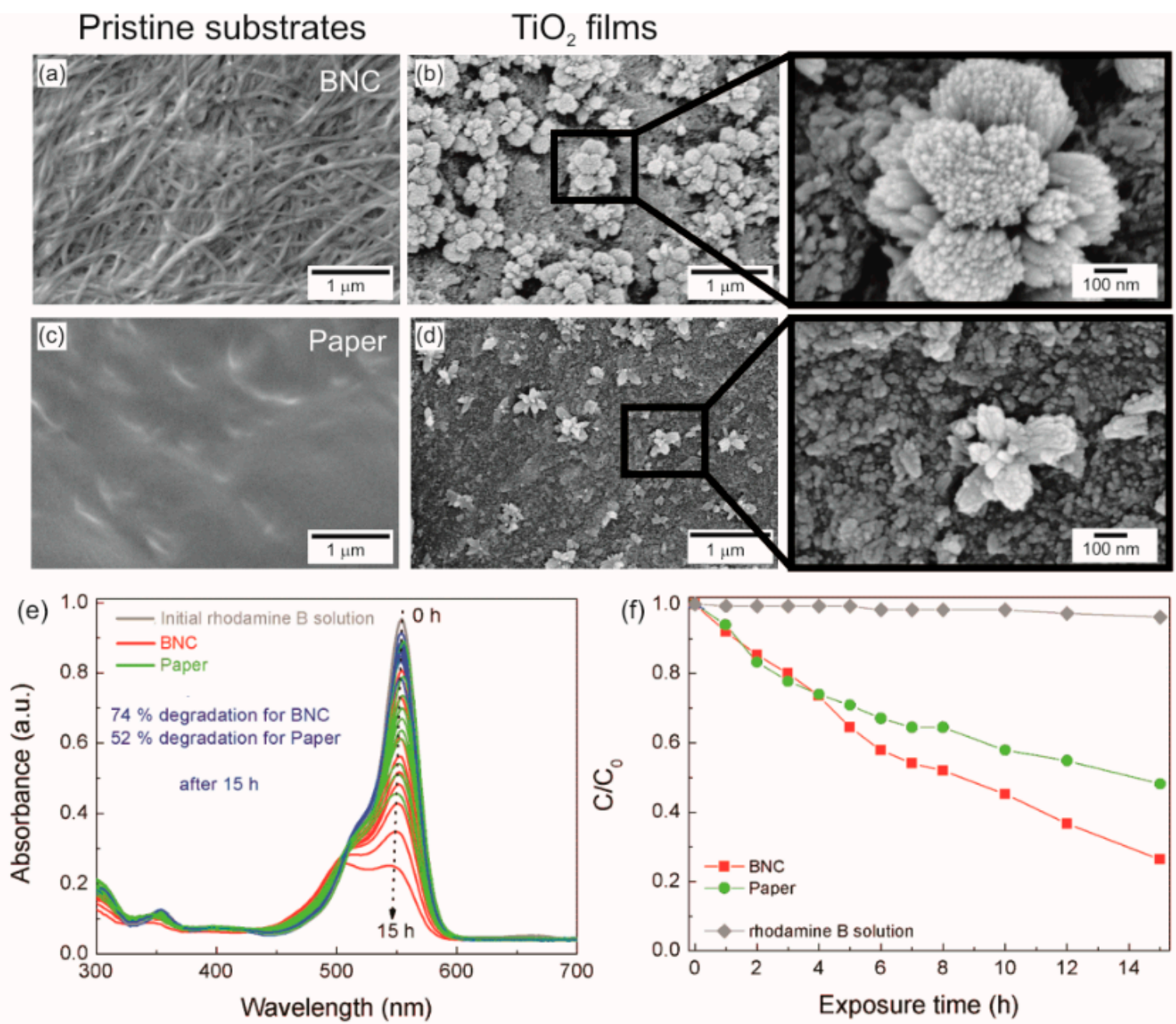

Figure 8. SEM images showing the $\mathrm{BNC}$ (a) and tracing paper (c) pristine substrates together with the $\mathrm{TiO}_{2}$ films grown on $\mathrm{BNC}(\mathbf{b})$ and tracing paper (d) substrates. The insets show the $\mathrm{TiO}_{2}$ films and the nanorod flower-like structures. Rhodamine $\mathrm{B}$ absorbance spectra at different solar light exposure times up to $15 \mathrm{~h}(\mathbf{e})$. Rhodamine $\mathrm{B}$ degradation ratio $\left(\mathrm{C} / \mathrm{C}_{0}\right)$ vs. solar simulating light exposure time (f). Reproduced with permission of Springer Nature [19].

Office paper was also used as substrates for growing $\mathrm{TiO}_{2}$ nanostructured films. Figure 9 showed the scanning electron microscopy (SEM) images of the pristine office paper (Figure 9a) and the $\mathrm{TiO}_{2}$ nanostructured films grown under microwave irradiation on the office paper substrate (Figure 9b). It can be observed that microwave synthesis totally covered the paper substrate, and a continuous nanostructured $\mathrm{TiO}_{2}$ film could be 
achieved. These films were investigated as photocatalysts, and their photocatalytic activity was assessed for Rhodamine B degradation under UV radiation (Figure 9c). The gradual rhodamine B degradation was observed. The photocatalysts were resistant to water immersion, and after the photocatalytic experiments, the papers could be recovered and dried for further tests. The direct growth of $\mathrm{TiO}_{2}$ on paper with chemical-based processes reduces the production costs of the photocatalysts due to the lack of parallel processes, such as seed layers, or annealing. An analogous study reported the photocatalytic degradation of Rhodamine B using office paper as a substrate under UV and solar radiation [12]. This study demonstrated the synthesis of $\mathrm{TiO}_{2}$ and $\mathrm{ZnO}$ nanostructures using hydrothermal synthesis assisted by microwave irradiation, using office, Whatman, and commercial hospital papers as substrates. Their photocatalytic activity was assessed, and higher Rhodamine B degradation was reported for photocatalysts grown on Whatman paper [12]. T. Freire et al. [192] reported the growth of $\mathrm{TiO}_{2}$ thin films composed by very fine particles of $\sim 11 \mathrm{~nm}$ on Whatman paper using hydrothermal synthesis assisted by microwave irradiation. These films had their photocatalytic activity tested with the photodegradation of Rhodamine B under solar radiation, and the effective contribution of paper on the final photocatalytic performance has been estimated.
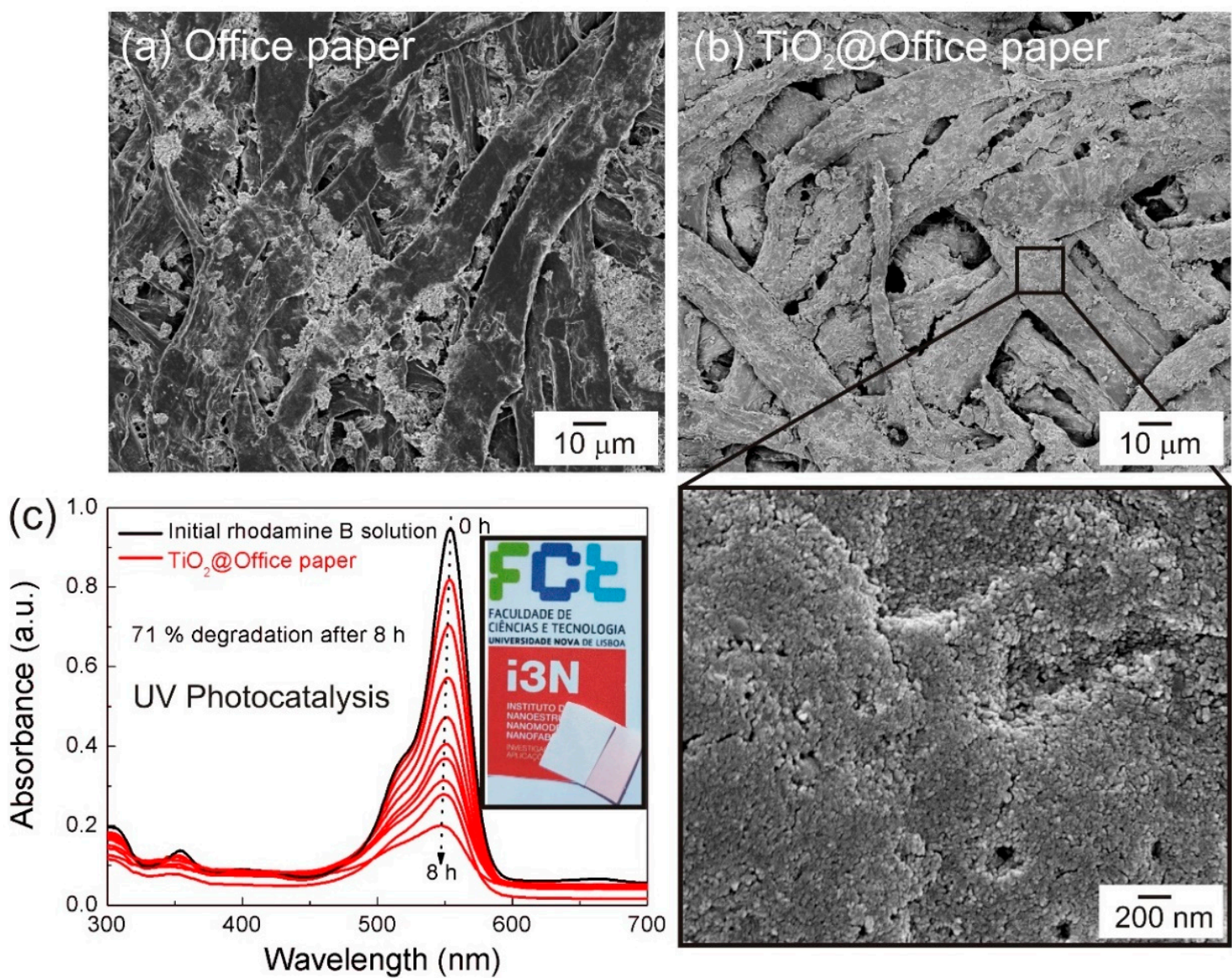

Figure 9. SEM images showing (a) the pristine office paper and (b) after a microwave-assisted hydrothermal synthesis. The inset magnifies the $\mathrm{TiO}_{2}$ nanostructured film grown on office paper substrate. (c) Rhodamine $\mathrm{B}$ absorbance spectra at different UV exposure times using the $\mathrm{TiO}_{2}$ nanostructured film on office paper together with the image of the photocatalytic paper before and after (pinkish color) experiments (71\% of degradation after $8 \mathrm{~h}$ using 3 lamps of $95 \mathrm{~W}$ aligned in parallel, from Osram, with an emission wavelength of $254 \mathrm{~nm}$, and Rhodamine B solution of $5 \mathrm{mg} / \mathrm{L}$ ). Photocatalytic experiments based on [19]. 


\section{2. $\mathrm{ZnO}$ Photocatalytic Paper}

Zinc oxide is also considered a promising photocatalyst for environmental remediation. In fact, it has been reported that $\mathrm{ZnO}$ exhibits higher efficiency in the photocatalytic degradation of some organic dyes than $\mathrm{TiO}_{2}$, i.e., methyl orange and Rhodamine 6G [193]. ZnO has a high surface reactivity owing to its large number of active surface defect states [20]. This material has a strong oxidation ability, chemical stability, enhanced photocatalytic activity, and a large free-exciton binding energy, in a way that the excitonic emission processes can be maintained at room temperature or above [30]. Moreover, it is non-toxic, earth abundant, biocompatible, biodegradable, environmentally friendly, low cost, and compatible with simple chemical synthesis. Just like $\mathrm{TiO}_{2}$, its wide band gap limits light absorption in the visible light region which is associated with the fast recombination of photogenerated charges, resulting in low photocatalytic efficiency [30].

$\mathrm{ZnO}$ is an $n$-type semiconductor with a direct and wide band gap of $3.37 \mathrm{eV}$ and a large exciton binding energy of $60 \mathrm{meV}$ at room temperature $[30,194]$. The common $\mathrm{ZnO}$ crystal structures are the rocksalt, wurtzite or cubic (zinc blende) structures. However, $\mathrm{ZnO}$ displays the wurtzite crystal structure at room temperature (Figure 10), with the highest thermodynamic stability among the three structures [30,195]. This wurtzite structure has a hexagonal unit cell with space group $P 6_{3} m c$ and lattice parameters, $a=0.3296 \mathrm{~nm}$ and $b=0.52065 \mathrm{~nm}$ [30]. The $\mathrm{ZnO}$ wurtzite structure has a tetrahedrally coordinated bonding geometry based on two interconnecting hexagonal closed packed sublattices, each of them consisting of one type of atom ( $\mathrm{Zn}$ or O) displaced alternatively along the threefold $c$-axis. It exhibits a positive polar plane that is rich in $\mathrm{Zn}^{2+}$ and negative polar plane that is rich in $\mathrm{O}^{2-}$. Each zinc ion has four oxygen neighbor ions in a tetrahedral configuration and vice versa $[30,196]$. The tetrahedral coordination is typical of $\mathrm{sp}^{3}$ covalent bonding, and this $\mathrm{Zn}^{2+}$ and $\mathrm{O}^{2-}$ tetrahedral coordination is the origin of a polar symmetry along the hexagonal axis. Moreover, the polarization effect is one of the major factors influencing the crystal growth of $\mathrm{ZnO}$ nanostructures [30].

The $c$-axis direction is referred to as [0001], while the surface perpendicular to the $c$-axis is the hexagonal (0001) plane [196]. The most common and stable $\mathrm{ZnO}$ wurtzite crystal exhibits the following face terminations: the polar $\mathrm{Zn}$ terminated $\{0001\}$ and $\mathrm{O}$ terminated $\{000 \overline{1}\}$ facets, and the non-polar $\{10 \overline{1} 0\}$ facets, containing an equal number of $\mathrm{Zn}$ and O atoms [62,194,197-199]. The polar facets possess distinct chemical and physical properties when compared to the non-polar ones [194].

It has been reported that the $\{0001\}$ facets terminated with $\mathrm{Zn}$ atoms are the most active facets among the various surfaces of $\mathrm{ZnO}$ nanomaterials. Thus, due to the high surface energy of $\{0001\}$ facets, the exposure of $\{0001\}$ facets may enhance the efficiency of photocatalysis. However, it has been shown that nanostructures with high percentages of exposed high-index facets also exhibited superior photocatalytic activity [200].

$\mathrm{ZnO}$ has also restrictions to its widespread use in photocatalysis under solar radiation as previously mentioned. Thus, several approaches have been suggested to overcome this limitation, including nonmetal and metal doping for reducing the band gap and improving the charge carrier separation, which shifts the absorption range of $\mathrm{ZnO}$ to the visible region [118]. Moreover, the surface functionalization of $\mathrm{ZnO}$ also has an impact on the final photocatalytic performance due to the narrowing of the material's surface band gap [201]. Another approach lies on making an enhanced heterojunction with a $p$-type semiconductor, for example, $\mathrm{CuO}$, to achieve superior photocatalytic activity [202]. 


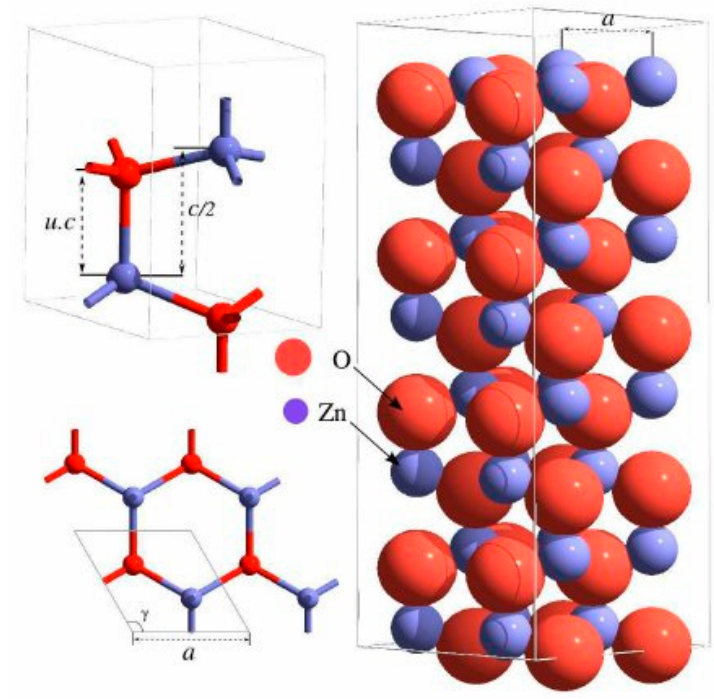

Figure 10. Bulk crystal structure of wurtzite Zinc oxide [203]. Reprinted Figure with permission from Simulation of reconstructions of the polar $\mathrm{ZnO}\{0001\}$ surfaces, as follows: H. Meskine and P. A. Mulheran, Phys. Rev. B 84, 165430, 2011. Copyright 2021 by the American Physical Society.

$\mathrm{ZnO}$ has been extensively investigated over the years as thin films or nanostructures and in fact, several $\mathrm{ZnO}$ structures have been described at the nanoscale. The most common are one-dimensional nanostructures, such as nanorods, nanotubes, nanofibers, nanowires, but also nanoplates, nanosheets, nanospheres, tetrapods, and nanoflowers, among others, have been described (Figure 11) [204-209]. To produce such a variety of structures, numerous and distinct techniques have been reported, including direct precipitation [210], the sol-gel method [211,212], hydrothermal [213,214] and solvothermal syntheses [101], microwave synthesis [96,97,215], chemical bath deposition [216], electrospinning [217], electrodeposition [218], electrospinning [102,105], magnetron sputtering [219,220], and spray pyrolysis [221], among others.
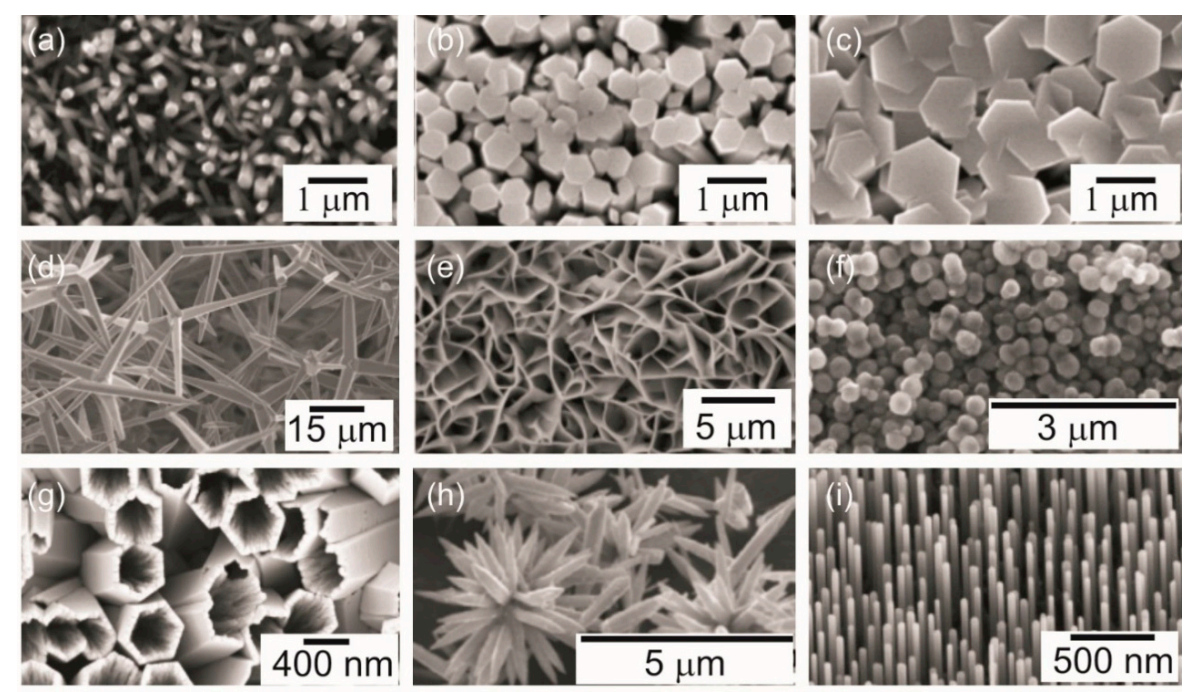

Figure 11. SEM images of several $\mathrm{ZnO}$ nanostructures. (a) $\mathrm{ZnO}$ nanorods [204], (b,c) $\mathrm{ZnO}$ nanoplates [204], (d) ZnO tetrapods [222], (e) ZnO nanosheets [205], (f) ZnO nanospheres [206], (g) $\mathrm{ZnO}$ nanotubes [207], (h) $\mathrm{ZnO}$ nanoflowers [209], and (i) aligned $\mathrm{ZnO}$ nanowire arrays [208]. Reprinted with permission from direct growth of freestanding $\mathrm{ZnO}$ tetrapod networks for multifunctional applications in photocatalysis, UV photodetection, and gas sensing, ACS Appl. Mater. Interfaces 2015, 7, 26, 14303-14316, copyright 2021 American Chemical Society [222], and Elsevier [204-209]. 
The growth of $\mathrm{ZnO}$ on paper substrates has also been reported previously. Araujo et al. [223] produced 3D SERS platforms based on $\mathrm{ZnO}$ nanorod arrays grown on paper substrates using a fast and low-temperature hydrothermal method assisted by microwave radiation. Pimentel et al. [11] produced paper-based UV sensors based on $\mathrm{ZnO}$ nanorods, also grown using a fast and low-temperature hydrothermal method assisted by microwave radiation. Two types of paper substrates were tested, i.e., tracing and Whatman papers. The effect of the synthesis temperature on $\mathrm{ZnO}$ nanostructures was investigated and an UV/Ozone treatment performed directly to the $\mathrm{ZnO}$ seed layer prior to microwave assisted synthesis revealed expressive differences regarding the formation of the $\mathrm{ZnO}$ nanostructures (Figure 12). Manekkathodi et al. [224] reported the production of prototype photoconducting devices and $\mathrm{PN}$ junction diodes were fabricated with aligned single-crystal $\mathrm{ZnO}$ nanowires and nanoneedles on paper using low temperature and a non-hazardous chemical solution.
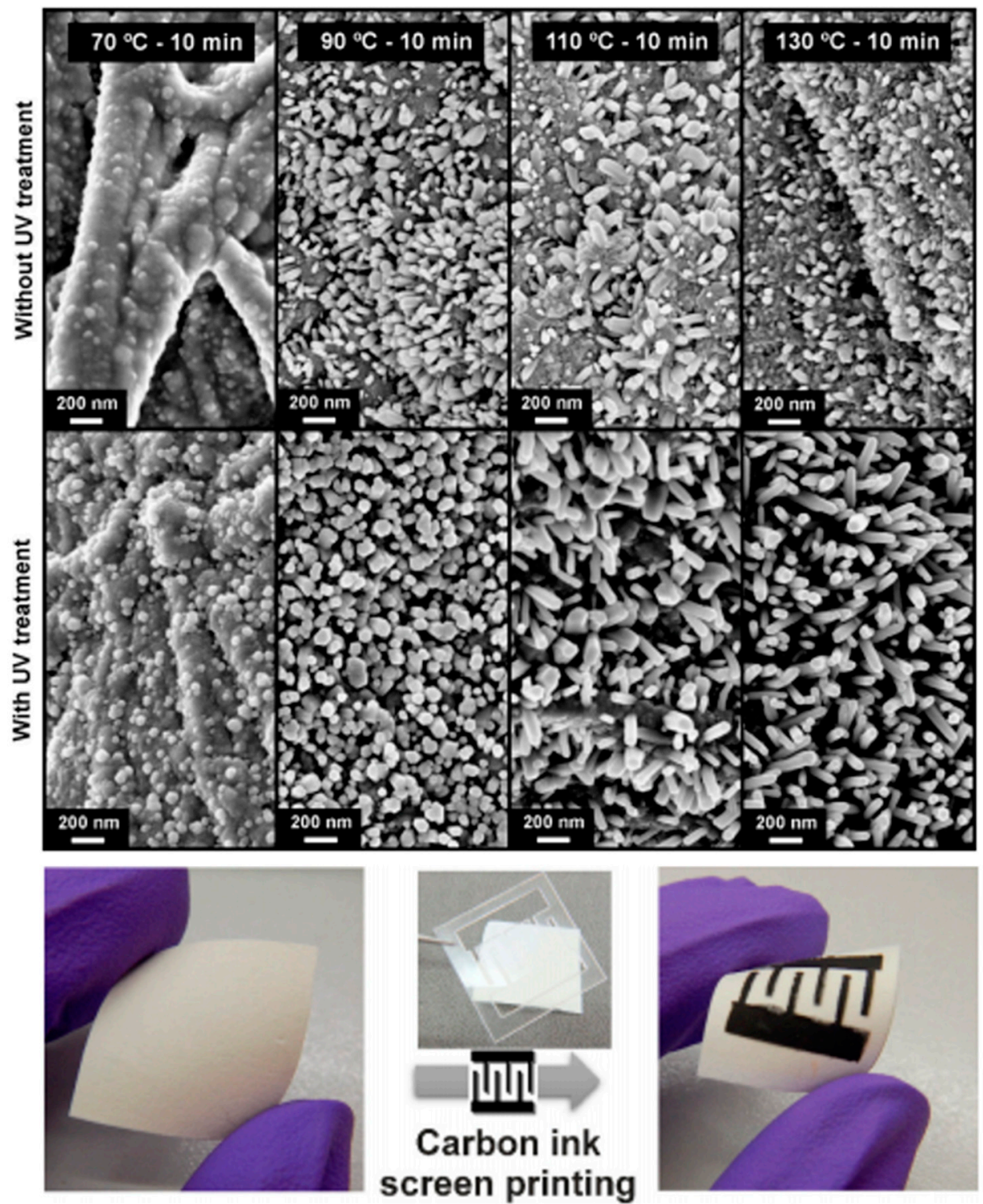

Figure 12. SEM images of the $\mathrm{ZnO}$ nanorods grown on Whatman paper with different temperatures in microwave synthesis. The effect of UV treatment has been investigated. The real image of the paper-based UV sensor is presented [11]. Reproduced with permission of MDPI [11].

The antibacterial activity against Escherichia coli of paper coated with $\mathrm{ZnO}$ nanoparticles has been reported in [225]. In another study, ZnO-cellulose composites coating paper 
were applied as antibacterial and antifungal agents [226]. A review manuscript dedicated to the preparation and antibacterial activity of cellulose/ $\mathrm{ZnO}$ composites has been published in [227].

When it comes to $\mathrm{ZnO}$ photocatalytic paper, some studies demonstrated the enhanced photocatalytic activity of such metal oxide material on paper, especially of 1D nanostructures, such as nanorods, nanowires, and nanofibers, due to their larger surface-to-volume ratio, when compared to thin films [20].

Baruah et al. [20] demonstrated that $\mathrm{ZnO}$ nanorods grown on paper supports prepared from soft wood pulp are promising photocatalysts. The produced paper embedded with $\mathrm{ZnO}$ nanorods in its porous matrix revealed enhanced photocatalytic degradation of methylene blue and methyl orange under visible light, being reused several times. Tsai et al. [54] reported a photocatalytic paper comprised of $\mathrm{Cu}_{2} \mathrm{O}$ and $\mathrm{Ag}$ nanoparticles decorating $\mathrm{ZnO}$ nanorods produced using a hydrothermal method, and its application in the visible light photodegradation of Rhodamine $\mathrm{B}$. The photocatalytic activity of pure ZnO-based paper and paper containing $\mathrm{Cu}_{2} \mathrm{O}$ and $\mathrm{Ag}$ separately or together have been tested, in which the paper with $\mathrm{Cu}_{2} \mathrm{O}$ and $\mathrm{Ag}$ nanoparticles co-decorating the $\mathrm{ZnO}$ nanorods demonstrated the best photocatalytic efficiency (Figure 13).
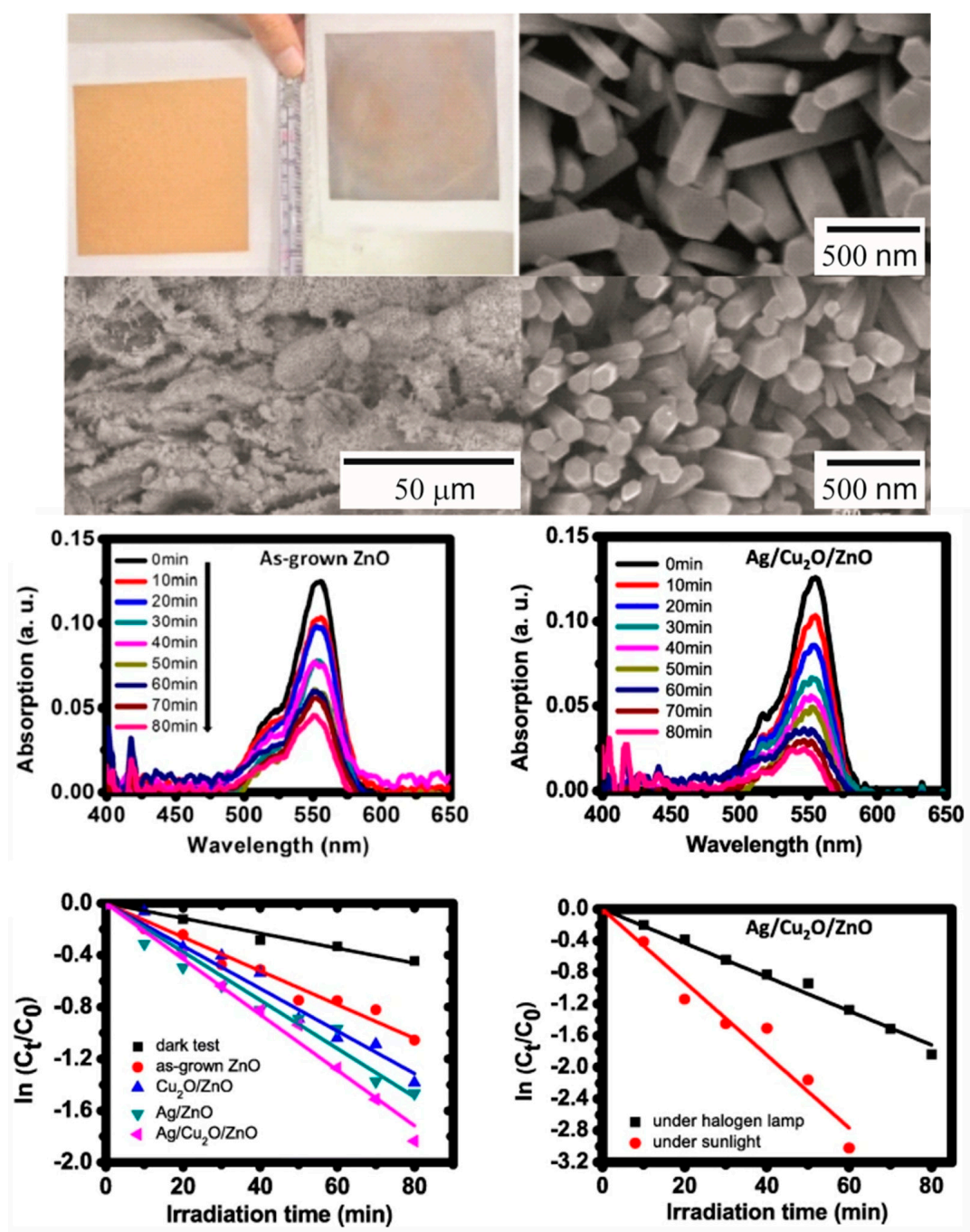

Figure 13. Real photographs of the kraft paper substrate and the paper with the $\mathrm{ZnO}$ nanorods. The SEM image of the papers containing the $\mathrm{ZnO}$ nanorods are presented together with their photocatalytic activity under visible light [54]. Reproduced with permission of Springer Nature [54]. 
A thorn-like $\mathrm{ZnO}$-multiwalled carbon nanotube hybrid paper produced with an atomic layer deposition followed by hydrothermal growth has been reported in [228]. Its photocatalytic performance was assessed under UV irradiation, enabling the photodegradation of Rhodamine $\mathrm{B}$ and good recyclability.

In an innovative approach, $\mathrm{Fe}_{2} \mathrm{O}_{3} / \mathrm{ZnO}$ hollow spheres with submicron pores were integrated in inks to produce stable photocatalytic papers by a spraying method. It was reported that the hollow spheres perfectly matched the cellulose networks within the paper due to the similar dimensions, and that the photocatalytic paper were able to efficiently degrade the 2,4,6-trichlorophenol under solar light irradiation [229].

A heterojunction of $\mathrm{TiO}_{2} / \mathrm{ZnO}$ nanostructures grown on paper substrates has been reported in [12]. Microwave synthesis was used for growing both layers and depending on the type of paper used, different $\mathrm{ZnO}$ structures were obtained (Figure 14). Continuous $\mathrm{ZnO}$ nanorod arrays were grown on Whatman paper, while on office paper, nanoplates that originated the nanoflower structures could be observed. The formation of nanoplates structures have been associated with the presence of calcium carbonate $\left(\mathrm{CaCO}_{3}\right)$ in office paper. The effect of oxalic acid has also been investigated, and an etching effect was observed on office paper with deterioration of the nanoplate's surface and laminar structures, and holes started to appear. The $\mathrm{ZnO} / \mathrm{TiO}_{2}$ heterostructures grown on office paper were tested as a photocatalyst under UV light. It was shown that the deteriorated structure of the nanoplates increased the photocatalytic activity due to the higher surface area of such materials.

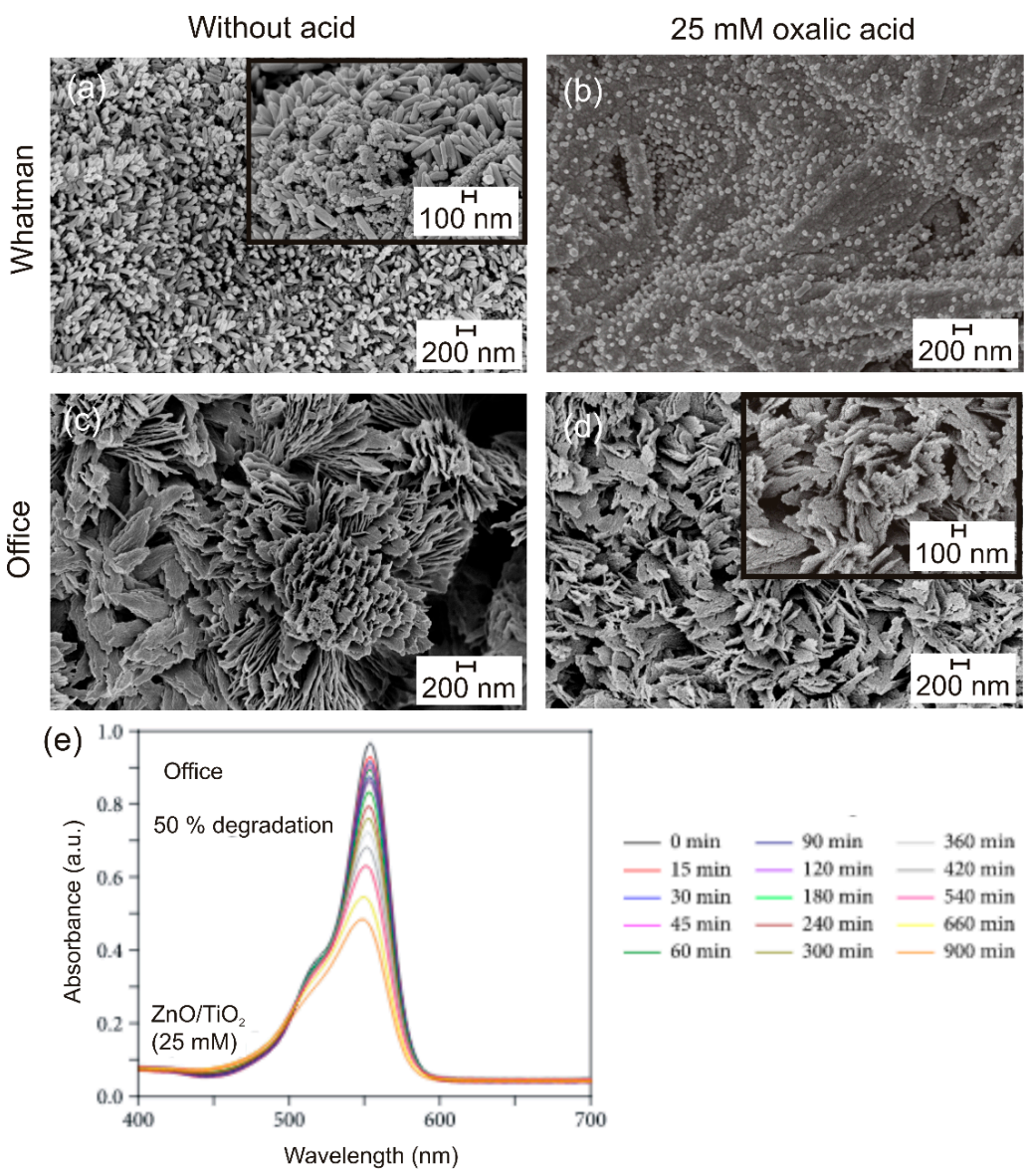

Figure 14. $\mathrm{ZnO} / \mathrm{TiO}_{2}$ heterostructures grown on Whatman and Office papers having $\mathrm{TiO}_{2}$ synthesized without acid and with $25 \mathrm{mM}$ of oxalic acid (a-d). The inset in (a) magnifies the heterostructure, while the inset in (d) evidences the surface modification with oxalic acid. (e) Rhodamine B photodegradation under UV light of the heterojunction grown on office paper and represented in (d) [12]. Reproduced with permission of Hindawi [12]. 
Other metal oxide-based papers had their photocatalytic activity investigated for environmental remediation; however, these studies are still scarce. A photocatalytic paper based on $\mathrm{Ag}_{2} \mathrm{O}$ has been reported, in which cellulose fibers and graphite fibers have been incorporated with the $\mathrm{Ag}_{2} \mathrm{O}$ nanoparticles. Its photocatalytic activity was evaluated with the degradation of methyl orange under UV, VIS or near-IR light, mostly covering the solar spectrum [230]. Another study reported a composite based on $\mathrm{BiVO}_{4} @$ diatomite/microcrystalline cellulose/poly (vinyl butyral) that was prepared using the electrospinning method. The photocatalytic activity of this paper was investigated with the photodegradation of methylene blue and formaldehyde under visible light [231].

The International Standard ISO 10678:2010 is an accepted standard experimental method for photocatalytic experiments and it specifies a method for the photocatalytic degradation of methylene blue [232]. Nevertheless, in most published studies, the photocatalytic parameters that can influence the final photodegradation vary expressively, including the light sources, the concentration of pollutants tested, and even the distance between the light source and the photocatalytic apparatus. Table 1 summarizes all the metal oxide-based photocatalytic papers discussed above, considering the paper-based materials, target pollutant, and light source.

Table 1. Summary of the metal oxide-based photocatalytic papers reported in literature.

\begin{tabular}{|c|c|c|c|}
\hline Material & Target Pollutant/Medium & Light Source & Reference \\
\hline Paper with $\mathrm{TiO}_{2}$ aggregates & Acetaldehyde in gas & Weak UV & [180] \\
\hline $\begin{array}{c}\text { Paper with } \mathrm{TiO}_{2} \text { supported on inorganic } \\
\text { fibers }\end{array}$ & Acetaldehyde in gas & UV & [181] \\
\hline $\begin{array}{c}\text { Paper with nano } \mathrm{TiO}_{2} \text { powders supported } \\
\text { on } \mathrm{X} \text { zeolite }\end{array}$ & Acetaldehyde in gas & VIS & [182] \\
\hline $\begin{array}{l}\text { Papers containing } \mathrm{TiO}_{2} \text { decorated with } \\
\text { AgBr nanoparticles }\end{array}$ & 2-propanol in gas & Sunlight & [183] \\
\hline $\begin{array}{c}\text { Paper with } \mathrm{TiO}_{2} \text { nanoparticles confined in } \\
\text { hollow silica capsules }\end{array}$ & 2-propanol in gas & UV & [55] \\
\hline $\begin{array}{l}\text { Cellulose-based material with } \mathrm{TiO}_{2} \\
\text { nanoparticles loaded on carbon fibers }\end{array}$ & Methyl orange in liquid & UV & [57] \\
\hline $\begin{array}{l}\text { Papers containing poly-dopamine-loaded } \\
\text { cellulose fiere together with pristine } \\
\text { cellulose fiere and } \mathrm{TiO}_{2} \text { nanoparticles }\end{array}$ & Methyl orange in liquid & UV & [58] \\
\hline $\begin{array}{l}\mathrm{TiO}_{2} \text {-coated non-woven paper with } \\
\text { colloidal } \mathrm{SiO}_{2} \text { binder }\end{array}$ & Rhodamine B in liquid & UV & [184] \\
\hline Paper with $\mathrm{TiO}_{2}$ nanosol & Blue indigo carmine in liquid & UV & [186] \\
\hline $\mathrm{TiO}_{2}$ hydrosols on paper sheets & Methylene blue in liquid & UV & {$[187]$} \\
\hline $\begin{array}{l}\text { Paper based on a } \mathrm{TiO}_{2} / \text { Sodium alginate } \\
\text { nanocomposite }\end{array}$ & $\begin{array}{l}\text { Chemical oxygen demand of } \\
\text { wastewater/liquid }\end{array}$ & UV & [185] \\
\hline Paper- $\mathrm{TiO}_{2}$ composite & 2-propanol in gas & Sunlight & [178] \\
\hline $\begin{array}{c}\text { Au nanoparticles decorating } \mathrm{TiO}_{2} \\
\text { nanowires onto hierarchically porous } \\
\text { carbon fiber paper }\end{array}$ & Styrene in gas & VIS & [177] \\
\hline $\begin{array}{l}\text { Papers composed by nanosized } \mathrm{TiO}_{2} \\
\text { supported on natural zeolite }\end{array}$ & Toluene in gas & UV & {$[188,189]$} \\
\hline $\begin{array}{l}\text { Paper formed by a composite of } \mathrm{TiO}_{2} / \mathrm{SiO}_{2} \\
\text { particles }\end{array}$ & Ethanol in gas & UV & [190] \\
\hline $\mathrm{BNC}$ with $\mathrm{TiO}_{2}$ nanostructured films & Rhodamine B in liquid & Sunlight & [19] \\
\hline $\begin{array}{c}\text { Papers with } \mathrm{TiO}_{2}, \mathrm{ZnO} \text { and } \mathrm{ZnO} / \mathrm{TiO}_{2} \\
\text { nanostructured films }\end{array}$ & Rhodamine B in liquid & UV and sunlight & [12] \\
\hline
\end{tabular}


Table 1. Cont.

\begin{tabular}{|c|c|c|c|}
\hline Material & Target Pollutant/Medium & Light Source & Reference \\
\hline Papers with $\mathrm{TiO}_{2}$ thin films & Rhodamine B in liquid & Sunlight & [192] \\
\hline Paper with $\mathrm{ZnO}$ nanorods & $\begin{array}{c}\text { Methylene blue and methyl orange in } \\
\text { liquid }\end{array}$ & VIS & {$[20]$} \\
\hline $\begin{array}{l}\text { Paper with } \mathrm{Cu}_{2} \mathrm{O} \text { and } \mathrm{Ag} \text { nanoparticles } \\
\text { decorating } \mathrm{ZnO} \text { nanorods }\end{array}$ & Rhodamine B in liquid & VIS & [54] \\
\hline $\begin{array}{l}\text { Thorn-like ZnO-multiwalled carbon } \\
\text { nanotube hybrid paper }\end{array}$ & Rhodamine B in liquid & UV & [228] \\
\hline Papers with $\mathrm{Fe}_{2} \mathrm{O}_{3} / \mathrm{ZnO}$ hollow spheres & 2,4,6-trichlorophenol in liquid & Sunlight & [229] \\
\hline Paper containing $\mathrm{Ag}_{2} \mathrm{O}$ nanoparticles & Methyl orange in liquid & UV, VIS or near-IR & [230] \\
\hline $\begin{array}{c}\text { Paper based of } \\
\mathrm{BiVO}_{4} @ \text { diatomite/microcrystalline } \\
\text { cellulose/ poly(vinyl butyral) }\end{array}$ & $\begin{array}{l}\text { Methylene blue in liquid and } \\
\text { formaldehyde in gas }\end{array}$ & VIS & [231] \\
\hline
\end{tabular}

All the approaches discussed in this review manuscript provide an overview on the versatility of using cellulose-based materials on photocatalysis. However, these materials still present some drawbacks, such as degradation under light exposure or the presence of impurities. An alternative to surpass these limitations is surface functionalization. In fact, functionalization strengthens thermal, mechanical and barrier properties [1] and increases surface absorption which, in the case of photocatalysis, influences the final performance. Moreover, it can create hydrophobic barriers or regions to contain compounds/reagents or pollutants. Cellulose functionalized with several binders (porphyrin, phthalocyanine, polyaniline (PAni)), and cellulose embedded with silver nanowires have been previously reported $[1,233,234]$. Thus, the integration of enhanced metal oxides as membranes, composites or grown/deposited in functionalized cellulose-based materials can originate highly photoactive papers to help environmental remediation.

\section{Conclusions and Future Perspectives}

This review summarized the latest developments in photocatalysis, focusing on metal oxides integrated on cellulose-based materials to originate enhanced photocatalytic papers. The work described the use of paper as a substrate, but also to form composites and membranes. The main characteristics of paper have been emphasized, including its lowcost and abundant character; moreover, it is environmentally friendly, flexible, foldable, recyclable, and lightweight. For photocatalysis, its 3D structure can contribute to enhance the photocatalytic activity, providing more active sites for the photoreaction.

Metal oxide nanomaterials are largely employed in photocatalysis, due to their high surface-to-volume ratios and high surface reaction activities. This work focused on nanostructured $\mathrm{TiO}_{2}$ and $\mathrm{ZnO}$ since both materials are largely employed in the photodegradation of organic compounds. Moreover, these materials are eco-friendly, earth abundant, inexpensive, nontoxic, easily produced, and compatible with wet-chemical synthesis. Different studies have been presented which have correlated structural properties to the final photocatalytic activity. The main photocatalytic limitations of these materials have been addressed, namely the fast recombination of electrons and holes and the limitation of solar spectrum absorption, with different approaches for overcoming those being discussed. Other metal oxide-based paper systems and their applications for environmental remediation have also been mentioned.

The future of photocatalytic paper is expected to rely on nanosized cellulose. It is imperative to develop sustainable and inexpensive production processes for nanocellulose and its scale-up to industrial levels. To improve the photocatalytic activity of nanocellulose, surface functionalization is critical. The cellulose functionalization also allows stacking different paper-based layers: for example, a composite of a $n$-type semiconductor/cellulose 
on top of a $p$-type semiconductor/cellulose (or vice versa), forming an enhanced photocatalytic heterojunction. Advanced 3D materials composed by a mixture of nano and micro-sized cellulose can also be relevant. The use of printing techniques is also an alternative to produce continuous photocatalytic films on nano-paper by directly printing inks containing the metal oxide nanostructures.

The increase in photocatalytic activity involves the development of better photocatalysts, i.e., metal oxide nanostructures or thin films. Several approaches have been discussed, from metal oxides decorated with nanoparticles, to doping with other elements, or even coupling with other semiconductors. However, extensive efforts are still needed for the development of innovative production strategies and tuned nanomaterials which are highly photoactive under solar radiation. Moreover, the deep understanding of the degradation mechanisms is still required.

The photocatalytic paper concept opens a wide number of possibilities, as these materials can be employed in varied applications, are easily adapted to different surfaces due to their high flexibility and have easy handling. Their disposable character and recyclability effectively contribute to environmental protection, while reducing costs.

Author Contributions: D.N. and A.P. were responsible for writing the review manuscript, R.B. participated in the review and editing, and R.M. and E.F. were responsible for supervising all the process. All authors have read and agreed to the published version of the manuscript.

Funding: This work was funded by National Funds through the FCT-Fundação para a Ciência e a Tecnologia, I.P., under the scope of the project UIDB/50025/2020-2023. The authors also acknowledge Fundação para a Ciência e a Tecnologia for funding the Project ICARUS under the reference PTDC/EAM-AMB/30989/2017. The work was also partially funded by the Nanomark collaborative project between INCM (Imprensa Nacional-Casa da Moeda) and CENIMAT/i3N. This work also received funding from the European Community's H2020 program under grant agreement No. 787410 (ERC-2018-AdG DIGISMART). The authors also acknowledge the funding of EC project SYNERGY H2020-WIDESPREAD-2020-5, CSA, proposal nº 952169.

Conflicts of Interest: The authors declare no conflict of interest.

\section{References}

1. Vicente, A.; Araujo, A.; Mendes, M.J.; Nunes, D.; Oliveira, M.J.; Sanchez-Sobrado, O.; Ferreira, M.P.; Aguas, H.; Fortunato, E.; Martins, R. Multifunctional cellulose-paper for light harvesting and smart sensing applications. J. Mater. Chem. C 2018, 6, 3143-3181. [CrossRef]

2. Mohamed, M.A.; Abd Mutalib, M.; Hir, Z.A.M.; Zain, M.F.M.; Mohamad, A.B.; Minggu, L.J.; Awang, N.A.; Salleh, W.N.W. An overview on cellulose-based material in tailoring bio-hybrid nanostructured photocatalysts for water treatment and renewable energy applications. Int. J. Biol. Macromol. 2017, 103, 1232-1256. [CrossRef]

3. Moon, R.J.; Martini, A.; Nairn, J.; Simonsen, J.; Youngblood, J. Cellulose nanomaterials review: Structure, properties and nanocomposites. Chem. Soc. Rev. 2011, 40, 3941-3994. [CrossRef]

4. Festucci-Buselli, R.A.; Otoni, W.C.; Joshi, C.P. Structure, organization, and functions of cellulose synthase complexes in higher plants. Braz. J. Plant Physiol. 2007, 19, 1-13. [CrossRef]

5. Poletto, M.; Pistor, V.; Zattera, A.J. Structural Characteristics and Thermal Properties of Native Cellulose; Intech: Rijeka, Croatia, 2013; Volume 2, pp. 45-68.

6. Gaspar, D.; Fernandes, S.N.; de Oliveira, A.G.; Fernandes, J.G.; Grey, P.; Pontes, R.V.; Pereira, L.; Martins, R.; Godinho, M.H.; Fortunato, E. Nanocrystalline cellulose applied simultaneously as the gate dielectric and the substrate in flexible field effect transistors. Nanotechnology 2014, 25, 094008. [CrossRef] [PubMed]

7. Fortunato, E.; Gaspar, D.; Duarte, P.; Pereira, L.; Águas, H.; Vicente, A.; Dourado, F.; Gama, M.; Martins, R. Chapter 11Optoelectronic Devices from Bacterial NanoCellulose. In Bacterial Nanocellulose; Gama, M., Dourado, F., Bielecki, S., Eds.; Elsevier: Amsterdam, The Netherlands, 2016; pp. 179-197. [CrossRef]

8. Gama, M.; Dourado, F.; Bielecki, S. Bacterial Nanocellulose: From Biotechnology to Bio-Economy; Elsevier Science: Amsterdam, The Netherlands, 2016.

9. Zschieschang, U.; Klauk, H. Organic transistors on paper: A brief review. J. Mater. Chem. C 2019, 7, 5522-5533. [CrossRef]

10. Vicente, A.; Âguas, H.; Mateus, T.; Araújo, A.; Lyubchyk, A.; Siitonen, S.; Fortunato, E.; Martins, R. Solar cells for self-sustainable intelligent packaging. J. Mater. Chem. A 2015, 3, 13226-13236. [CrossRef]

11. Pimentel, A.; Samouco, A.; Nunes, D.; Araújo, A.; Martins, R.; Fortunato, E. Ultra-Fast Microwave Synthesis of ZnO Nanorods on Cellulose Substrates for UV Sensor Applications. Materials 2017, 10, 1308. [CrossRef] 
12. Matias, M.L.; Nunes, D.; Pimentel, A.; Ferreira, S.H.; Borda d Agua, R.; Duarte, M.P.; Fortunato, E.; Martins, R. Paper-Based Nanoplatforms for Multifunctional Applications. J. Nanomater. 2019, 2019, 16. [CrossRef]

13. Nunes, D.; Pimentel, A.; Gonçalves, A.; Pereira, S.; Branquinho, R.; Barquinha, P.; Fortunato, E.; Martins, R. Metal oxide nanostructures for sensor applications. Semicond. Sci. Technol. 2019, 34, 043001. [CrossRef]

14. Singh, A.T.; Lantigua, D.; Meka, A.; Taing, S.; Pandher, M.; Camci-Unal, G. Paper-Based Sensors: Emerging Themes and Applications. Sensors 2018, 18, 2838. [CrossRef] [PubMed]

15. Nunes, D.; Freire, T.; Barranger, A.; Vieira, J.; Matias, M.; Pereira, S.; Pimentel, A.; Cordeiro, N.J.; Fortunato, E.; Martins, R. TiO 2 Nanostructured Films for Electrochromic Paper Based-Devices. Appl. Sci. 2020, 10, 1200. [CrossRef]

16. Lang, A.W.; Österholm, A.M.; Reynolds, J.R. Paper-Based Electrochromic Devices Enabled by Nanocellulose-Coated Substrates. Adv. Funct. Mater. 2019, 29, 1903487. [CrossRef]

17. Hu, J.; Wang, S.; Wang, L.; Li, F.; Pingguan-Murphy, B.; Lu, T.J.; Xu, F. Advances in paper-based point-of-care diagnostics. Biosens. Bioelectron. 2014, 54, 585-597. [CrossRef]

18. Costa, M.N.; Veigas, B.; Jacob, J.M.; Santos, D.S.; Gomes, J.; Baptista, P.V.; Martins, R.; Inácio, J.; Fortunato, E. A low cost, safe, disposable, rapid and self-sustainable paper-based platform for diagnostic testing: Lab-on-paper. Nanotechnology 2014, $25,094006$. [CrossRef]

19. Nunes, D.; Pimentel, A.; Araujo, A.; Calmeiro, T.; Panigrahi, S.; Pinto, J.; Barquinha, P.; Gama, M.; Fortunato, E.; Martins, R. Enhanced UV Flexible Photodetectors and Photocatalysts Based on $\mathrm{TiO}_{2}$ Nanoplatforms. Top. Catal. 2018, 61, 1591-1606. [CrossRef]

20. Baruah, S.; Jaisai, M.; Imani, R.; Nazhad, M.M.; Dutta, J. Photocatalytic paper using zinc oxide nanorods. Sci. Technol. Adv. Mater. 2010, 11, 055002. [CrossRef]

21. Yan, L.; Liu, B.; Li, W.; Zhao, T.; Wang, Y.; Zhao, Q. Multiscale cellulose based self-assembly of hierarchical structure for photocatalytic degradation of organic pollutant. Cellulose 2020, 27, 5241-5253. [CrossRef]

22. Available online: https://www.un.org/sustainabledevelopment/water-and-sanitation/ (accessed on 20 February 2021).

23. Fujishima, A.; Honda, K. Electrochemical Photolysis of Water at a Semiconductor Electrode. Nature 1972, 238, 37-38. [CrossRef]

24. Marschall, R.; Wang, L. Non-metal doping of transition metal oxides for visible-light photocatalysis. Catal. Today 2014, 225, 111-135. [CrossRef]

25. Ameta, R.; Solanki, M.S.; Benjamin, S.; Ameta, S.C. Chapter 6-Photocatalysis. In Advanced Oxidation Processes for Waste Water Treatment; Ameta, S.C., Ameta, R., Eds.; Academic Press: Cambridge, MA, USA, 2018; pp. 135-175. [CrossRef]

26. Pawar, M.; Topcu Sendoğdular, S.; Gouma, P. A Brief Overview of $\mathrm{TiO}_{2}$ Photocatalyst for Organic Dye Remediation: Case Study of Reaction Mechanisms Involved in $\mathrm{Ce}^{-\mathrm{TiO}_{2}}$ Photocatalysts System. J. Nanomater. 2018, 2018, 5953609. [CrossRef]

27. Khokhra, R.; Bharti, B.; Lee, H.-N.; Kumar, R. Visible and UV photo-detection in ZnO nanostructured thin films via simple tuning of solution method. Sci. Rep. 2017, 7, 15032. [CrossRef] [PubMed]

28. Yang, X.; Wang, D. Photocatalysis: From Fundamental Principles to Materials and Applications. ACS Appl. Energy Mater. 2018, 1 , 6657-6693. [CrossRef]

29. Zhu, S.; Wang, D. Photocatalysis: Basic Principles, Diverse Forms of Implementations and Emerging Scientific Opportunities. Adv. Energy Mater. 2017, 7, 1700841. [CrossRef]

30. Lee, K.M.; Lai, C.W.; Ngai, K.S.; Juan, J.C. Recent developments of zinc oxide based photocatalyst in water treatment technology: A review. Water Res. 2016, 88, 428-448. [CrossRef]

31. Ong, C.B.; Ng, L.Y.; Mohammad, A.W. A review of ZnO nanoparticles as solar photocatalysts: Synthesis, mechanisms and applications. Renew. Sustain. Energy Rev. 2018, 81, 536-551. [CrossRef]

32. Yáñez, E.; Santander, P.; Contreras, D.; Yáñez, J.; Cornejo, L.; Mansilla, H.D. Homogeneous and heterogeneous degradation of caffeic acid using photocatalysis driven by UVA and solar light. J. Environ. Sci. Health Part A Toxic/Hazard. Subst. Environ. Eng. 2016, 51, 78-85. [CrossRef]

33. Ibhadon, A.O.; Fitzpatrick, P. Heterogeneous Photocatalysis: Recent Advances and Applications. Catalysts 2013, 3, 189-218. [CrossRef]

34. Gusain, R.; Gupta, K.; Joshi, P.; Khatri, O.P. Adsorptive removal and photocatalytic degradation of organic pollutants using metal oxides and their composites: A comprehensive review. Adv. Colloid Interface Sci. 2019, 272, 102009. [CrossRef] [PubMed]

35. Danish, M.S.S.; Estrella, L.L.; Alemaida, I.M.A.; Lisin, A.; Moiseev, N.; Ahmadi, M.; Nazari, M.; Wali, M.; Zaheb, H.; Senjyu, T. Photocatalytic Applications of Metal Oxides for Sustainable Environmental Remediation. Metals 2021, 11, 80. [CrossRef]

36. Pimentel, A.; Nunes, D.; Pereira, S.; Martins, R.; Fortunato, E. Photocatalytic Activity of $\mathrm{TiO}_{2}$ Nanostructured Arrays Prepared by Microwave-Assisted Solvothermal Method. In Semiconductor Photocatalysis—Materials, Mechanisms and Applications; Cao, W., Ed.; InTech: Rijeka, Croatia, 2016; Chapter 3. [CrossRef]

37. Nunes, D.; Pimentel, A.; Santos, L.; Barquinha, P.; Fortunato, E.; Martins, R. Photocatalytic TiO 2 Nanorod Spheres and Arrays Compatible with Flexible Applications. Catalysts 2017, 7, 60. [CrossRef]

38. Nunes, D.; Pimentel, A.; Pinto, J.V.; Calmeiro, T.R.; Nandy, S.; Barquinha, P.; Pereira, L.; Carvalho, P.A.; Fortunato, E.; Martins, R. Photocatalytic behavior of $\mathrm{TiO}_{2}$ films synthesized by microwave irradiation. Catal. Today 2016, 278 Pt 2, 262-270. [CrossRef]

39. Chakrabarti, S.; Dutta, B. Photocatalytic degradation of model textile dyes in wastewater using ZnO as semiconductor catalyst. J. Hazard. Mater. 2004, 112, 269-278. [CrossRef] [PubMed] 
40. Ye, Y.; Feng, Y.; Bruning, H.; Yntema, D.; Rijnaarts, H.H.M. Photocatalytic degradation of metoprolol by $\mathrm{TiO}_{2}$ nanotube arrays and UV-LED: Effects of catalyst properties, operational parameters, commonly present water constituents, and photo-induced reactive species. Appl. Catal. B Environ. 2018, 220, 171-181. [CrossRef]

41. Beydoun, D.R.; Amal, R.; Low, G.; McEvoy, S. Role of Nanoparticles in Photocatalysis. J. Nanoparticle Res. 1999, 1, $439-458$. [CrossRef]

42. Lan, Y.; Lu, Y.; Ren, Z. Mini review on photocatalysis of titanium dioxide nanoparticles and their solar applications. Nano Energy 2013, 2, 1031-1045. [CrossRef]

43. Nam, Y.; Lim, J.H.; Ko, K.C.; Lee, J.Y. Photocatalytic activity of $\mathrm{TiO}_{2}$ nanoparticles: A theoretical aspect. J. Mater. Chem. A 2019, 7, 13833-13859. [CrossRef]

44. Hong, X.; Wang, Z.; Cai, W.; Lu, F.; Zhang, J.; Yang, Y.; Ma, N.; Liu, Y. Visible-Light-Activated Nanoparticle Photocatalyst of Iodine-Doped Titanium Dioxide. Chem. Mater. 2005, 17, 1548-1552. [CrossRef]

45. Yu, Y.; Wen, W.; Qian, X.-Y.; Liu, J.-B.; Wu, J.-M. UV and visible light photocatalytic activity of $\mathrm{Au} / \mathrm{TiO}_{2}$ nanoforests with Anatase/Rutile phase junctions and controlled Au locations. Sci. Rep. 2017, 7, 41253. [CrossRef]

46. Gao, F.; Chen, X.; Yin, K.; Dong, S.; Ren, Z.; Yuan, F.; Yu, T.; Zou, Z.; Liu, J.M. Visible-light photocatalytic properties of weak magnetic $\mathrm{BiFeO}_{3}$ nanoparticles. Adv. Mater. 2007, 19, 2889-2892. [CrossRef]

47. Wang, P.; Huang, B.; Dai, Y.; Whangbo, M.-H. Plasmonic photocatalysts: Harvesting visible light with noble metal nanoparticles. Phys. Chem. Chem. Phys. 2012, 14, 9813-9825. [CrossRef]

48. Wang, R.; Cai, X.; Shen, F. Preparation of $\mathrm{TiO}_{2}$ hollow microspheres by a novel vesicle template method and their enhanced photocatalytic properties. Ceram. Int. 2013, 39, 9465-9470. [CrossRef]

49. Chen, L.; Yang, S.; Mader, E.; Ma, P.-C. Controlled synthesis of hierarchical $\mathrm{TiO}_{2}$ nanoparticles on glass fibres and their photocatalytic performance. Dalton Trans. 2014, 43, 12743-12753. [CrossRef] [PubMed]

50. Nam, H.J.; Amemiya, T.; Murabayashi, M.; Itoh, K. Photocatalytic Activity of Sol-Gel TiO 2 Thin Films on Various Kinds of Glass Substrates: The Effects of Na+ and Primary Particle Size. J. Phys. Chem. B 2004, 108, 8254-8259. [CrossRef]

51. Rampaul, A.; Parkin, I.P.; O’Neill, S.A.; DeSouza, J.; Mills, A.; Elliott, N. Titania and tungsten doped titania thin films on glass; active photocatalysts. Polyhedron 2003, 22, 35-44. [CrossRef]

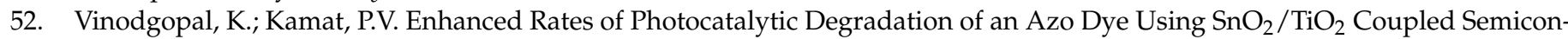
ductor Thin Films. Environ. Sci. Technol. 1995, 29, 841-845. [CrossRef]

53. Qi, K.; Xin, J.H. Room-Temperature Synthesis of Single-Phase Anatase $\mathrm{TiO}_{2}$ by Aging and its Self-Cleaning Properties. ACS Appl. Mater. Interfaces 2010, 2, 3479-3485. [CrossRef]

54. Tsai, C.-E.; Yeh, S.-M.; Chen, C.-H.; Lin, H.-N. Flexible Photocatalytic Paper with $\mathrm{Cu}_{2} \mathrm{O}$ and Ag Nanoparticle-Decorated ZnO Nanorods for Visible Light Photodegradation of Organic Dye. Nanoscale Res. Lett. 2019, 14, 204. [CrossRef]

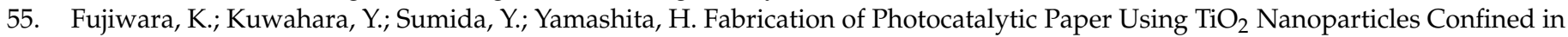
Hollow Silica Capsules. Langmuir 2017, 33, 288-295. [CrossRef]

56. Pelton, R.; Geng, X.; Brook, M. Photocatalytic paper from colloidal $\mathrm{TiO}_{2}$-fact or fantasy. Adv. Colloid Interface Sci. 2006, 127, 43-53. [CrossRef]

57. Zhang, J.; Liu, W.; Wang, P.; Qian, K. Photocatalytic behavior of cellulose-based paper with $\mathrm{TiO}_{2}$ loaded on carbon fibers. J. Environ. Chem. Eng. 2013, 1, 175-182. [CrossRef]

58. Qin, Z.; Liu, W.; Chen, H.; Chen, J.; Wang, H.; Song, Z. Preparing photocatalytic paper with improved catalytic activity by in situ loading poly-dopamine on cellulose fibre. Bull. Mater. Sci. 2019, 42, 54. [CrossRef]

59. Khan, M.M.; Adil, S.F.; Al-Mayouf, A. Metal oxides as photocatalysts. J. Saudi Chem. Soc. 2015, 19, 462-464. [CrossRef]

60. Nunes, D.; Pimentel, A.; Barquinha, P.; Carvalho, P.A.; Fortunato, E.; Martins, R. $\mathrm{Cu}_{2} \mathrm{O}$ polyhedral nanowires produced by microwave irradiation. J. Mater. Chem. C 2014, 2, 6097-6103. [CrossRef]

61. Wu, H.B.; Chen, J.S.; Hng, H.H.; Wen Lou, X. Nanostructured metal oxide-based materials as advanced anodes for lithium-ion batteries. Nanoscale 2012, 4, 2526-2542. [CrossRef] [PubMed]

62. Pimentel, A.; Rodrigues, J.; Duarte, P.; Nunes, D.; Costa, F.M.; Monteiro, T.; Martins, R.; Fortunato, E. Effect of solvents on ZnO nanostructures synthesized by solvothermal method assisted by microwave radiation: A photocatalytic study. J. Mater. Sci. 2015, 50, 5777-5787. [CrossRef]

63. Kolmakov, A.; Moskovits, M. Chemical sensing and catalysis by one-dimensional metal-oxide nanostructures. Annu. Rev. Mater. Res. 2004, 34, 151-180. [CrossRef]

64. Devan, R.S.; Patil, R.A.; Lin, J.-H.; Ma, Y.-R. One-Dimensional Metal-Oxide Nanostructures: Recent Developments in Synthesis, Characterization, and Applications. Adv. Funct. Mater. 2012, 22, 3326-3370. [CrossRef]

65. Ansari, A.A.; Alhoshan, M.; Alsalhi, M.; Aldwayyan, A. Nanostructured metal oxides based enzymatic electrochemical biosensors. In Biosensors; InTech: Rijeka, Croatia, 2010. [CrossRef]

66. Walia, S.; Balendhran, S.; Nili, H.; Zhuiykov, S.; Rosengarten, G.; Wang, Q.H.; Bhaskaran, M.; Sriram, S.; Strano, M.S.; Kalantarzadeh, K. Transition metal oxides-Thermoelectric properties. Prog. Mater. Sci. 2013, 58, 1443-1489. [CrossRef]

67. Guo, T.; Yao, M.-S.; Lin, Y.-H.; Nan, C.-W. A comprehensive review on synthesis methods for transition-metal oxide nanostructures. CrystEngComm 2015, 17, 3551-3585. [CrossRef]

68. Karunakaran, C.; Senthilvelan, $\mathrm{S}$. $\mathrm{Fe}_{2} \mathrm{O}_{3}$-photocatalysis with sunlight and UV light: Oxidation of aniline. Electrochem. Commun. 2006, 8, 95-101. [CrossRef] 
69. Moma, J.; Baloyi, J. Modified titanium dioxide for photocatalytic applications. In Photocatalysts—Applications and Attributes; Intech: London, UK, 2019; Volume 18. [CrossRef]

70. Wang, C.; Yin, L.; Zhang, L.; Xiang, D.; Gao, R. Metal Oxide Gas Sensors: Sensitivity and Influencing Factors. Sensors 2010, 10, 2088. [CrossRef]

71. Nunes, D.; Santos, L.; Pimentel, A.; Barquinha, P.; Pereira, L.; Fortunato, E.; Martins, R. Metal Oxide Nanostructures: Synthesis, Properties and Applications; Elsevier Science: Amsterdam, The Netherlands, 2018.

72. Gautam, S.; Agrawal, H.; Thakur, M.; Akbari, A.; Sharda, H.; Kaur, R.; Amini, M. Metal oxides and metal organic frameworks for the photocatalytic degradation: A review. J. Environ. Chem. Eng. 2020, 8, 103726. [CrossRef]

73. Rani, M.; Shanker, U.; Chaurasia, A.K. Catalytic potential of laccase immobilized on transition metal oxides nanomaterials: Degradation of alizarin red S dye. J. Environ. Chem. Eng. 2017, 5, 2730-2739. [CrossRef]

74. Rovisco, A.; Branquinho, R.; Deuermeier, J.; Freire, T.; Fortunato, E.; Martins, R.; Barquinha, P. Shape Effect of Zinc-Tin Oxide Nanostructures on Photodegradation of Methylene Blue and Rhodamine B under UV and Visible Light. ACS Appl. Nano Mater. 2021, 4, 1149-1161. [CrossRef]

75. Danish, M.S.S.; Bhattacharya, A.; Stepanova, D.; Mikhaylov, A.; Grilli, M.L.; Khosravy, M.; Senjyu, T. A Systematic Review of Metal Oxide Applications for Energy and Environmental Sustainability. Metals 2020, 10, 1604. [CrossRef]

76. Nandiyanto, A.B.D.; Zaen, R.; Oktiani, R. Correlation between crystallite size and photocatalytic performance of micrometer-sized monoclinic WO3 particles. Arab. J. Chem. 2020, 13, 1283-1296. [CrossRef]

77. Dittmann, R. 9-Stoichiometry in epitaxial oxide thin films. In Epitaxial Growth of Complex Metal Oxides; Koster, G., Huijben, M., Rijnders, G., Eds.; Woodhead Publishing: Sawston, UK, 2015; pp. 231-261. [CrossRef]

78. Tan, H.; Zhao, Z.; Zhu, W.-B.; Coker, E.N.; Li, B.; Zheng, M.; Yu, W.; Fan, H.; Sun, Z. Oxygen Vacancy Enhanced Photocatalytic Activity of Pervoskite $\mathrm{SrTiO}_{3}$. ACS Appl. Mater. Interfaces 2014, 6, 19184-19190. [CrossRef]

79. Khan, I.; Saeed, K.; Khan, I. Nanoparticles: Properties, applications and toxicities. Arabian J. Chem. 2019, 12, 908-931. [CrossRef]

80. Chen, Y.; Jia, G.; Hu, Y.; Fan, G.; Tsang, Y.H.; Li, Z.; Zou, Z. Two-dimensional nanomaterials for photocatalytic $\mathrm{CO}_{2}$ reduction to solar fuels. Sustain. Energy Fuels 2017, 1, 1875-1898. [CrossRef]

81. Nakata, K.; Fujishima, A. $\mathrm{TiO}_{2}$ photocatalysis: Design and applications. J. Photochem. Photobiol. C Photochem. Rev. 2012, 13, 169-189. [CrossRef]

82. Sugunan, A.; Warad, H.C.; Boman, M.; Dutta, J. Zinc oxide nanowires in chemical bath on seeded substrates: Role of hexamine. J. Sol-Gel Sci. Technol. 2006, 39, 49-56. [CrossRef]

83. Han, S.-Y.; Lee, D.-H.; Chang, Y.-J.; Ryu, S.-O.; Lee, T.-J.; Chang, C.-H. The growth mechanism of nickel oxide thin films by room-temperature chemical bath deposition. J. Electrochem. Soc. 2006, 153, C382. [CrossRef]

84. Antonelli, D.M.; Ying, J.Y. Synthesis of hexagonally packed mesoporous $\mathrm{TiO}_{2}$ by a modified sol-gel method. Angew. Chem. Int. Ed. Engl. 1995, 34, 2014-2017. [CrossRef]

85. Kim, I.D.; Rothschild, A. Nanostructured metal oxide gas sensors prepared by electrospinning. Polym. Adv. Technol. 2011, 22, 318-325. [CrossRef]

86. Monk, P.; Chester, S.L. Electro-deposition of films of electrochromic tungsten oxide containing additional metal oxides. Electrochim. Acta 1993, 38, 1521-1526. [CrossRef]

87. Bohannan, E.W.; Shumsky, M.G.; Switzer, J.A. Epitaxial electrodeposition of copper (I) oxide on single-crystal gold (100). Chem. Mater. 1999, 11, 2289-2291. [CrossRef]

88. Rydosz, A.; Brudnik, A.; Staszek, K. Metal oxide thin films prepared by magnetron sputtering technology for volatile organic compound detection in the microwave frequency range. Materials 2019, 12, 877. [CrossRef] [PubMed]

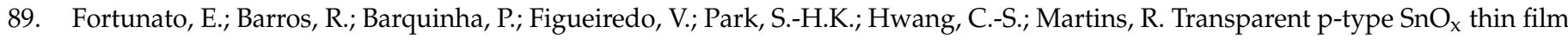
transistors produced by reactive $\mathrm{rf}$ magnetron sputtering followed by low temperature annealing. J. Appl. Phys. Lett. 2010, 97, 052105. [CrossRef]

90. Assuncao, V.; Fortunato, E.; Marques, A.; Aguas, H.; Ferreira, I.; Costa, M.; Martins, R.J.T.S.F. Influence of the deposition pressure on the properties of transparent and conductive $\mathrm{ZnO}$ : Ga thin-film produced by rf sputtering at room temperature. Thin Solid Film. 2003, 427, 401-405. [CrossRef]

91. Rodrigues, J.; Fernandes, A.J.; Monteiro, T.; Costa, F.M.J.C. A review on the laser-assisted flow deposition method: Growth of ZnO micro and nanostructures. CrystEngComm 2019, 21, 1071-1090. [CrossRef]

92. Santos, N.; Rodrigues, J.; Holz, T.; Sedrine, N.B.; Sena, A.; Neves, A.; Costa, F.; Monteiro, T. Luminescence studies on SnO 2 and $\mathrm{SnO}_{2}$ : Eu nanocrystals grown by laser assisted flow deposition. Phys. Chem. Chem. Phys. 2015, 17, 13512-13519. [CrossRef]

93. Pavan, M.; Rühle, S.; Ginsburg, A.; Keller, D.A.; Barad, H.-N.; Sberna, P.M.; Nunes, D.; Martins, R.; Anderson, A.Y.; Zaban, A. $\mathrm{TiO}_{2} / \mathrm{Cu}_{2} \mathrm{O}$ all-oxide heterojunction solar cells produced by spray pyrolysis. Sol. Energy Mater. Sol. Cells 2015, 132, 549-556. [CrossRef]

94. Sutorik, A.C.; Laine, R.M.; Marchal, J.; Johns, T.; Hinklin, T. Mixed-Metal Oxide Particles by Liquid Feed Flame Spray Pyrolysis of Oxide Precursors in Oxygenated Solvents. U.S. Patent 7,220,398, 22 May 2007.

95. Pimentel, A.; Nunes, D.; Duarte, P.; Rodrigues, J.; Costa, F.M.; Monteiro, T.; Martins, R.; Fortunato, E. Synthesis of Long ZnO Nanorods under Microwave Irradiation or Conventional Heating. J. Phys. Chem. C 2014, 118, 14629-14639. [CrossRef]

96. Pimentel, A.; Ferreira, S.; Nunes, D.; Calmeiro, T.; Martins, R.; Fortunato, E. Microwave Synthesized ZnO Nanorod Arrays for UV Sensors: A Seed Layer Annealing Temperature Study. Materials 2016, 9, 299. [CrossRef] [PubMed] 
97. Pimentel, A.; Araujo, A.; Coelho, B.J.; Nunes, D.; Oliveira, M.J.; Mendes, M.J.; Aguas, H.; Martins, R.; Fortunato, E. 3D ZnO/Ag Surface-Enhanced Raman Scattering on Disposable and Flexible Cardboard Platforms. Materials 2017, 10, 1351. [CrossRef]

98. Chirayil, T.; Zavalij, P.Y.; Whittingham, M.S. Hydrothermal synthesis of vanadium oxides. Chem. Mater. 1998, 10, 2629-2640. [CrossRef]

99. Kardarian, K.; Nunes, D.; Sberna, P.M.; Ginsburg, A.; Keller, D.A.; Pinto, J.V.; Deuermeier, J.; Anderson, A.Y.; Zaban, A.; Martins, $\mathrm{R}$. Effect of $\mathrm{Mg}$ doping on $\mathrm{Cu}_{2} \mathrm{O}$ thin films and their behavior on the $\mathrm{TiO}_{2} / \mathrm{Cu}_{2} \mathrm{O}$ heterojunction solar cells. Sol. Energy Mater. Sol. Cells 2016, 147, 27-36. [CrossRef]

100. Chavali, M.S.; Nikolova, M.P. Metal oxide nanoparticles and their applications in nanotechnology. SN Appl. Sci. 2019, 1, 607. [CrossRef]

101. Ha, L.P.P.; Vinh, T.H.T.; Thuy, N.T.B.; Thi, C.M.; Viet, P.V. Visible-light-driven photocatalysis of anisotropic silver nanoparticles decorated on $\mathrm{ZnO}$ nanorods: Synthesis and characterizations. J. Environ. Chem. Eng. 2021, 9, 105103. [CrossRef]

102. Di Mauro, A.; Zimbone, M.; Fragalà, M.E.; Impellizzeri, G. Synthesis of ZnO nanofibers by the electrospinning process. Mater. Sci. Semicond. Process. 2016, 42, 98-101. [CrossRef]

103. Ghosh, M.; Lohrasbi, M.; Chuang, S.S.; Jana, S.C.J.C. Mesoporous titanium dioxide nanofibers with a significantly enhanced photocatalytic activity. ChemCatChem 2016, 8, 2525-2535. [CrossRef]

104. Nalbandian, M.J.; Greenstein, K.E.; Shuai, D.; Zhang, M.; Choa, Y.-H.; Parkin, G.F.; Myung, N.V.; Cwiertny, D.M. Tailored Synthesis of Photoactive $\mathrm{TiO}_{2}$ Nanofibers and $\mathrm{Au} / \mathrm{TiO}_{2}$ Nanofiber Composites: Structure and Reactivity Optimization for Water Treatment Applications. Environ. Sci. Technol. 2015, 49, 1654-1663. [CrossRef]

105. Pei, C.C.; Leung, W.W.-F. Photocatalytic degradation of Rhodamine B by $\mathrm{TiO}_{2} / \mathrm{ZnO}$ nanofibers under visible-light irradiation. Sep. Purif. Technol. 2013, 114, 108-116. [CrossRef]

106. Shi, W.; Li, M.; Ren, H.; Guo, F.; Huang, X.; Shi, Y.; Tang, Y. Construction of a 0D/1D composite based on Au nanoparticles $/ \mathrm{CuBi}_{2} \mathrm{O}_{4}$ microrods for efficient visible-light-driven photocatalytic activity. Beilstein J. Nanotechnol. 2019, 10, 1360-1367. [CrossRef]

107. Wang, J.; Liu, Y.; Chen, X.; Chen, C.; Chen, P.; Wang, Z.; Duan, Y. Functional Metal Oxides in Perovskite Solar Cells. ChemPhysChem 2019, 20, 2580-2586. [CrossRef]

108. Bai, J.; Zhou, B. Titanium Dioxide Nanomaterials for Sensor Applications. Chem. Rev. 2014, 114, 10131-10176. [CrossRef] [PubMed]

109. Bernacka-Wojcik, I.; Senadeera, R.; Wojcik, P.J.; Silva, L.B.; Doria, G.; Baptista, P.; Aguas, H.; Fortunato, E.; Martins, R. Inkjet printed and "doctor blade" $\mathrm{TiO}_{2}$ photodetectors for DNA biosensors. Biosens. Bioelectron. 2010, 25, 1229-1234. [CrossRef]

110. Zhang, J.; Liu, J.; Peng, Q.; Wang, X.; Li, Y. Nearly monodisperse $\mathrm{Cu}_{2} \mathrm{O}$ and $\mathrm{CuO}$ nanospheres: Preparation and applications for sensitive gas sensors. Chem. Mater. 2006, 18, 867-871. [CrossRef]

111. Raible, I.; Burghard, M.; Schlecht, U.; Yasuda, A.; Vossmeyer, T. $\mathrm{V}_{2} \mathrm{O}_{5}$ nanofibres: Novel gas sensors with extremely high sensitivity and selectivity to amines. Sens. Actuators B Chem. 2005, 106, 730-735.

112. Dey, A. Semiconductor metal oxide gas sensors: A review. Mater. Sci. Eng. B 2018, 229, 206-217. [CrossRef]

113. Abideen, Z.U.; Kim, J.-H.; Lee, J.-H.; Kim, J.-Y.; Mirzaei, A.; Kim, S. Electrospun Metal Oxide Composite Nanofibers Gas Sensors: A Review. J. Korean Ceram. Soc. 2017, 54, 366-379. [CrossRef]

114. Liu, Y.; Yang, Y. Recent Progress of $\mathrm{TiO}_{2}$-Based Anodes for Li Ion Batteries. J. Nanomater. 2016, 2016, 15. [CrossRef]

115. Wang, X.; Cao, X.; Bourgeois, L.; Guan, H.; Chen, S.; Zhong, Y.; Tang, D.M.; Li, H.; Zhai, T.; Li, L. N-Doped Graphene-SnO 2 Sandwich Paper for High-Performance Lithium-Ion Batteries. Adv. Funct. Mater. 2012, 22, 2682-2690. [CrossRef]

116. Subalakshmi, P.; Sivashanmugam, A. CuO nano hexagons, an efficient energy storage material for Li-ion battery application. $J$. Alloys Compd. 2017, 690, 523-531. [CrossRef]

117. Lee, J.; Jo, C.; Park, B.; Hwang, W.; Lee, H.I.; Yoon, S.; Lee, J.J.N. Simple fabrication of flexible electrodes with high metaloxide content: Electrospun reduced tungsten oxide/carbon nanofibers for lithium ion battery applications. Nanoscale 2014, 6, 10147-10155. [CrossRef]

118. Mirzaeifard, Z.; Shariatinia, Z.; Jourshabani, M.; Rezaei Darvishi, S.M. ZnO Photocatalyst Revisited: Effective Photocatalytic Degradation of Emerging Contaminants Using S-Doped ZnO Nanoparticles under Visible Light Radiation. Ind. Eng. Chem. Res. 2020, 59, 15894-15911. [CrossRef]

119. Rathee, D.; Arya, S.; Kumar, M. Analysis of $\mathrm{TiO}_{2}$ for microelectronic applications: Effect of deposition methods on their electrical properties. Front. Optoelectron. China 2011, 4, 349-358. [CrossRef]

120. Di Paola, A.; Bellardita, M.; Palmisano, L. Brookite, the least known $\mathrm{TiO}_{2}$ photocatalyst. Catalysts 2013, 3, 36-73. [CrossRef]

121. Guo, Q.; Zhou, C.; Ma, Z.; Yang, X. Fundamentals of $\mathrm{TiO}_{2}$ Photocatalysis: Concepts, Mechanisms, and Challenges. Adv. Mater. 2019, 31, 1901997. [CrossRef]

122. Rocquefelte, X.; Goubin, F.; Koo, H.-J.; Whangbo, M.-H.; Jobic, S. Investigation of the Origin of the Empirical Relationship between Refractive Index and Density on the Basis of First Principles Calculations for the Refractive Indices of Various TiO $\mathrm{Phases}$ Inorg. Chem. 2004, 43, 2246-2251. [CrossRef] [PubMed]

123. Mo, S.-D.; Ching, W.Y. Electronic and optical properties of three phases of titanium dioxide: Rutile, anatase, and brookite. Phys. Rev. B 1995, 51, 13023-13032. [CrossRef] [PubMed] 
124. Allen, N.S.; Mahdjoub, N.; Vishnyakov, V.; Kelly, P.J.; Kriek, R.J. The effect of crystalline phase (anatase, brookite and rutile) and size on the photocatalytic activity of calcined polymorphic titanium dioxide $\left(\mathrm{TiO}_{2}\right)$. Polym. Degrad. Stab. 2018, 150, 31-36. [CrossRef]

125. Zhang, H.; Banfield, J.F. Structural Characteristics and Mechanical and Thermodynamic Properties of Nanocrystalline $\mathrm{TiO}_{2}$. Chem. Rev. 2014, 114, 9613-9644. [CrossRef]

126. Reyes-Coronado, D.; Rodríguez-Gattorno, G.; Espinosa-Pesqueira, M.; Cab, C.; De Coss, R.; Oskam, G. Phase-pure TiO 2 nanoparticles: Anatase, brookite and rutile. Nanotechnology 2008, 19, 145605. [CrossRef] [PubMed]

127. Kawahara, T.; Konishi, Y.; Tada, H.; Tohge, N.; Nishii, J.; Ito, S. A Patterned $\mathrm{TiO}_{2}$ (Anatase)/ $\mathrm{TiO}_{2}$ (Rutile) Bilayer-Type Photocatalyst: Effect of the Anatase/Rutile Junction on the Photocatalytic Activity. Angew. Chem. 2002, 114, 2935-2937. [CrossRef]

128. Andersson, M.; Österlund, L.; Ljungström, S.; Palmqvist, A. Preparation of Nanosize Anatase and $\mathrm{Rutile} \mathrm{TiO}_{2}$ by $\mathrm{Hydrothermal}$ Treatment of Microemulsions and Their Activity for Photocatalytic Wet Oxidation of Phenol. J. Phys. Chem. B 2002, 106, 10674-10679. [CrossRef]

129. Luttrell, T.; Halpegamage, S.; Tao, J.; Kramer, A.; Sutter, E.; Batzill, M. Why is anatase a better photocatalyst than rutile?-Model studies on epitaxial $\mathrm{TiO}_{2}$ films. Sci. Rep. 2014, 4, 4043. [CrossRef]

130. Zhang, J.; Zhou, P.; Liu, J.; Yu, J. New understanding of the difference of photocatalytic activity among anatase, rutile and brookite $\mathrm{TiO}_{2}$. Phys. Chem. Chem. Phys. 2014, 16, 20382-20386. [CrossRef]

131. Kandiel, T.A.; Robben, L.; Alkaim, A.; Bahnemann, D. Brookite versus anatase $\mathrm{TiO}_{2}$ photocatalysts: Phase transformations and photocatalytic activities. Photochem. Photobiol. Sci. 2013, 12, 602-609. [CrossRef]

132. Boppella, R.; Basak, P.; Manorama, S.V. Viable Method for the Synthesis of Biphasic $\mathrm{TiO}_{2}$ Nanocrystals with Tunable Phase Composition and Enabled Visible-Light Photocatalytic Performance. ACS Appl. Mater. Interfaces 2012, 4, 1239-1246. [CrossRef]

133. Wang, Y.; Li, L.; Huang, X.; Li, Q.; Li, G. New insights into fluorinated $\mathrm{TiO}_{2}$ (brookite, anatase and rutile) nanoparticles as efficient photocatalytic redox catalysts. RSC Adv. 2015, 5, 34302-34313. [CrossRef]

134. Nakajima, H.; Mori, T.; Shen, Q.; Toyoda, T. Photoluminescence study of mixtures of anatase and rutile $\mathrm{TiO}_{2}$ nanoparticles: Influence of charge transfer between the nanoparticles on their photoluminescence excitation bands. Chem. Phys. Lett. 2005, 409, 81-84. [CrossRef]

135. Mutuma, B.K.; Shao, G.N.; Kim, W.D.; Kim, H.T. Sol-gel synthesis of mesoporous anatase-brookite and anatase-brookite-rutile $\mathrm{TiO}_{2}$ nanoparticles and their photocatalytic properties. J. Colloid Interface Sci. 2015, 442, 1-7. [CrossRef] [PubMed]

136. Zhang, J.; Wu, B.; Huang, L.; Liu, P.; Wang, X.; Lu, Z.; Xu, G.; Zhang, E.; Wang, H.; Kong, Z.; et al. Anatase nano-TiO 2 with exposed curved surface for high photocatalytic activity. J. Alloys Compd. 2016, 661, 441-447. [CrossRef]

137. Xu, H.; Ouyang, S.; Liu, L.; Reunchan, P.; Umezawa, N.; Ye, J. Recent advances in $\mathrm{TiO}_{2}$-based photocatalysis. J. Mater. Chem. A 2014, 2, 12642-12661. [CrossRef]

138. Khan, M.M.; Ansari, S.A.; Pradhan, D.; Ansari, M.O.; Han, D.H.; Lee, J.; Cho, M.H. Band gap engineered $\mathrm{TiO}_{2}$ nanoparticles for visible light induced photoelectrochemical and photocatalytic studies. J. Mater. Chem. A 2014, 2, 637-644. [CrossRef]

139. George, S.; Pokhrel, S.; Ji, Z.; Henderson, B.L.; Xia, T.; Li, L.; Zink, J.I.; Nel, A.E.; Mädler, L. Role of Fe Doping in Tuning the Band Gap of $\mathrm{TiO}_{2}$ for the Photo-Oxidation-Induced Cytotoxicity Paradigm. J. Am. Chem. Soc. 2011, 133, 11270-11278. [CrossRef]

140. Umebayashi, T.; Yamaki, T.; Itoh, H.; Asai, K. Band gap narrowing of titanium dioxide by sulfur doping. Appl. Phys. Lett. 2002, 81, 454-456. [CrossRef]

141. Pan, X.; Yang, M.-Q.; Fu, X.; Zhang, N.; Xu, Y.-J. Defective $\mathrm{TiO}_{2}$ with oxygen vacancies: Synthesis, properties and photocatalytic applications. Nanoscale 2013, 5, 3601-3614. [CrossRef]

142. Bakbolat, B.; Daulbayev, C.; Sultanov, F.; Beissenov, R.; Umirzakov, A.; Mereke, A.; Bekbaev, A.; Chuprakov, I. Recent Developments of $\mathrm{TiO}_{2}$-Based Photocatalysis in the Hydrogen Evolution and Photodegradation: A Review. Nanomaterials 2020, 10, 1790. [CrossRef]

143. Al Jitan, S.; Palmisano, G.; Garlisi, C. Synthesis and Surface Modification of $\mathrm{TiO}_{2}-\mathrm{Based}$ Photocatalysts for the Conversion of $\mathrm{CO}_{2}$. Catalysts 2020, 10, 227. [CrossRef]

144. Ghosh, M.; Liu, J.; Chuang, S.S.C.; Jana, S.C. Fabrication of Hierarchical $\mathrm{V}_{2} \mathrm{O}_{5}$ Nanorods on $\mathrm{TiO}_{2}$ Nanofibers and Their Enhanced Photocatalytic Activity under Visible Light. Chem CatChem 2018, 10, 3305-3318. [CrossRef]

145. Zhao, X.; Zhang, Y.; Wu, M.; Szeto, W.; Wang, Y.; Pan, W.; Leung, D.Y.C. Carbon doped ultra-small TiO 2 coated on carbon cloth for efficient photocatalytic toluene degradation under visible LED light irradiation. Appl. Surf. Sci. 2020, 527, 146780. [CrossRef]

146. Alcudia-Ramos, M.A.; Fuentez-Torres, M.O.; Ortiz-Chi, F.; Espinosa-González, C.G.; Hernández-Como, N.; García-Zaleta, D.S.; Kesarla, M.K.; Torres-Torres, J.G.; Collins-Martínez, V.; Godavarthi, S. Fabrication of g- $\mathrm{C}_{3} \mathrm{~N}_{4} / \mathrm{TiO}_{2}$ heterojunction composite for enhanced photocatalytic hydrogen production. Ceram. Int. 2020, 46, 38-45. [CrossRef]

147. Park, H.; Park, Y.; Kim, W.; Choi, W. Surface modification of $\mathrm{TiO}_{2}$ photocatalyst for environmental applications. J. Photochem. Photobiol. C Photochem. Rev. 2013, 15, 1-20. [CrossRef]

148. Zaleska-Medynska, A. Doped-TiO 2 : A review. Recent Pat. Eng. 2008, 2, 157-164. [CrossRef]

149. Zoubi, W.A.; Al-Hamdani, A.A.S.; Sunghun, B.; Ko, Y.G. A review on $\mathrm{TiO}_{2}$-based composites for superior photocatalytic activity. Rev. Inorg. Chem. 2021. [CrossRef]

150. Wang, Y.; Wang, Q.; Zhan, X.; Wang, F.; Safdar, M.; He, J. Visible light driven type II heterostructures and their enhanced photocatalysis properties: A review. Nanoscale 2013, 5. [CrossRef] [PubMed]

151. Li, G.; Wang, G.; Hong, J. Synthesis and characterization of rutile $\mathrm{TiO}_{2}$ nanowhiskers. J. Mater. Res. 1999, 14, 3346-3354. [CrossRef] 
152. Verma, R.; Gangwar, J.; Srivastava, A.K. Multiphase $\mathrm{TiO}_{2}$ nanostructures: A review of efficient synthesis, growth mechanism, probing capabilities, and applications in bio-safety and health. RSC Adv. 2017, 7, 44199-44224. [CrossRef]

153. Zhang, X.; Wang, Y.; Liu, B.; Sang, Y.; Liu, H. Heterostructures construction on $\mathrm{TiO}_{2}$ nanobelts: A powerful tool for building high-performance photocatalysts. Appl. Catal. B Environ. 2017, 202, 620-641. [CrossRef]

154. Yang, H.G.; Zeng, H.C. Preparation of Hollow Anatase $\mathrm{TiO}_{2}$ Nanospheres via Ostwald Ripening. J. Phys. Chem. B 2004, 108, 3492-3495. [CrossRef]

155. Lin, J.; Heo, Y.-U.; Nattestad, A.; Sun, Z.; Wang, L.; Kim, J.H.; Dou, S.X. 3D hierarchical rutile TiO 2 and metal-free organic sensitizer producing dye-sensitized solar cells 8.6\% conversion efficiency. Sci. Rep. 2014, 4, 1-8. [CrossRef]

156. Kranthi Kiran, A.S.; Madhumathi, K.; Sampath Kumar, T.S. Electrosprayed titania nanocups for protein delivery. Colloid Interface Sci. Commun. 2016, 12, 17-20. [CrossRef]

157. Negishi, N.; Iyoda, T.; Hashimoto, K.; Fujishima, A. Preparation of transparent $\mathrm{TiO}_{2}$ thin film photocatalyst and its photocatalytic activity. J. Chem. Lett. 1995, 24, 841-842. [CrossRef]

158. Yu, J.; Zhao, X.; Zhao, Q. Effect of surface structure on photocatalytic activity of $\mathrm{TiO}_{2}$ thin films prepared by sol-gel method. Thin Solid Film. 2000, 379, 7-14. [CrossRef]

159. Evtushenko, Y.M.; Romashkin, S.V.; Trofimov, N.S.; Chekhlova, T.K. Optical Properties of $\mathrm{TiO}_{2}$ Thin Films. Phys. Procedia 2015, 73, 100-107. [CrossRef]

160. Sagadevan, S. Synthesis and electrical properties of $\mathrm{TiO}_{2}$ nanoparticles using a wet chemical technique. Am. J. Nanosci. Nanotechnol. 2014, 1, 27. [CrossRef]

161. Fernández, I.E.; Rodríguez-Páez, J.E. Wet-chemical preparation of $\mathrm{TiO}_{2}$-nanostructures using different solvents: Effect of CTAB concentration and tentative mechanism of particle formation. J. Alloys Compd. 2019, 780, 756-771. [CrossRef]

162. Wu, J.-M.; Shih, H.C.; Wu, W.-T.; Tseng, Y.-K.; Chen, I.C. Thermal evaporation growth and the luminescence property of TiO 2 nanowires. J. Cryst. Growth 2005, 281, 384-390. [CrossRef]

163. Boyadzhiev, S.; Georgieva, V.; Rassovska, M. Characterization of reactive sputtered $\mathrm{TiO}_{2}$ thin films for gas sensor applications. J. Phys. Conf. Ser. 2010, 253, 012040. [CrossRef]

164. Sanchez-Sobrado, O.; Mendes, M.J.; Haque, S.; Mateus, T.; Araujo, A.; Aguas, H.; Fortunato, E.; Martins, R. Colloidal-lithographed $\mathrm{TiO}_{2}$ photonic nanostructures for solar cell light trapping. J. Mater. Chem. C 2017, 5, 6852-6861. [CrossRef]

165. Sreekantan, S.; Saharudin, K.A.; Wei, L.C. Formation of $\mathrm{TiO}_{2}$ nanotubes via anodization and potential applications for photocatalysts, biomedical materials, and photoelectrochemical cell. IOP Conf. Ser. Mater. Sci. Eng. 2011, 21, 012002. [CrossRef]

166. Prakasam, H.E.; Shankar, K.; Paulose, M.; Varghese, O.K.; Grimes, C.A. A new benchmark for $\mathrm{TiO}_{2}$ nanotube array growth by anodization. J. Phys. Chem. C 2007, 111, 7235-7241. [CrossRef]

167. Jiang, L.C.; Zhang, W.D. Electrodeposition of $\mathrm{TiO}_{2}$ nanoparticles on multiwalled carbon nanotube arrays for hydrogen peroxide sensing. Electroanalysis 2009, 21, 988-993. [CrossRef]

168. Macak, J.M.; Gong, B.G.; Hueppe, M.; Schmuki, P.J.A.M. Filling of $\mathrm{TiO}_{2}$ Nanotubes by Self-Doping and Electrodeposition. Adv. Mater. 2007, 19, 3027-3031. [CrossRef]

169. Kim, J.-H.; Lee, J.-H.; Kim, J.-Y.; Kim, S.S.J.A.S. Synthesis of aligned $\mathrm{TiO}_{2}$ nanofibers using electrospinning. Appl. Sci. 2018, 8, 309.

170. Lee, D.; Rho, Y.; Allen, F.I.; Minor, A.M.; Ko, S.H.; Grigoropoulos, C.P. Synthesis of hierarchical TiO 2 nanowires with denselypacked and omnidirectional branches. Nanoscale 2013, 5, 11147-11152. [CrossRef]

171. Yu, J.; Wang, Y.; Xiao, W. Enhanced photoelectrocatalytic performance of $\mathrm{SnO}_{2} / \mathrm{TiO}_{2}$ rutile composite films. J. Mater. Chem. A 2013, 1, 10727-10735. [CrossRef]

172. Zhao, X.; Liu, M.; Zhu, Y. Fabrication of porous $\mathrm{TiO}_{2}$ film via hydrothermal method and its photocatalytic performances. Thin Solid Film. 2007, 515, 7127-7134. [CrossRef]

173. Chen, Q.; Qian, Y.; Chen, Z.; Wu, W.; Chen, Z.; Zhou, G.; Zhang, Y. Hydrothermal epitaxy of highly oriented TiO 2 thin films on silicon. Appl. Phys. Lett. 1995, 66, 1608-1610. [CrossRef]

174. Wei, N.; Cui, H.; Song, Q.; Zhang, L.; Song, X.; Wang, K.; Zhang, Y.; Li, J.; Wen, J.; Tian, J. Ag $\mathrm{O}_{2}$ nanoparticle/TiO 2 nanobelt heterostructures with remarkable photo-response and photocatalytic properties under $\mathrm{UV}$, visible and near-infrared irradiation. Appl. Catal. B Environ. 2016, 198, 83-90. [CrossRef]

175. Kondo, T.; Nagao, S.; Yanagishita, T.; Nguyen, N.T.; Lee, K.; Schmuki, P.; Masuda, H. Ideally ordered porous TiO 2 prepared by anodization of pretextured Ti by nanoimprinting process. Electrochem. Commun. 2015, 50, 73-76. [CrossRef]

176. Zhang, Y.X.; Li, G.H.; Jin, Y.X.; Zhang, Y.; Zhang, J.; Zhang, L.D. Hydrothermal synthesis and photoluminescence of TiO 2 nanowires. Chem. Phys. Lett. 2002, 365, 300-304. [CrossRef]

177. Shi, J.; Chen, J.; Li, G.; An, T.; Yamashita, H. Fabrication of $\mathrm{Au} / \mathrm{TiO}_{2}$ nanowires@carbon fiber paper ternary composite for visible-light photocatalytic degradation of gaseous styrene. Catal. Today 2017, 281, 621-629. [CrossRef]

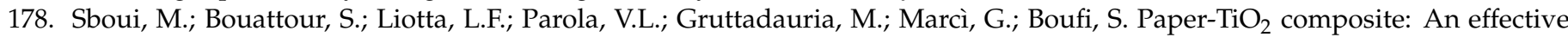
photocatalyst for 2-propanol degradation in gas phase. J. Photochem. Photobiol. A Chem. 2018, 350, 142-151. [CrossRef]

179. Hu, T.; Sun, X.; Sun, H.; Yu, M.; Lu, F.; Liu, C.; Lian, J. Flexible free-standing graphene- $\mathrm{TiO}_{2}$ hybrid paper for use as lithium ion battery anode materials. Carbon 2013, 51, 322-326. [CrossRef]

180. Hirokazu, M.; Makoto, T.; Shinichi, K.; Kazuhito, H.; Akira, F. Photoactive $\mathrm{TiO}_{2}$ Containing Paper: Preparation and Its Photocatalytic Activity under Weak UV Light Illumination. Chem. Lett. 1995, 24, 767-768. [CrossRef] 
181. Iguchi, Y.; Ichiura, H.; Kitaoka, T.; Tanaka, H. Preparation and characteristics of high performance paper containing titanium dioxide photocatalyst supported on inorganic fiber matrix. Chemosphere 2003, 53, 1193-1199. [CrossRef]

182. Izadyar, S.; Fatemi, S. Fabrication of X Zeolite Based Modified Nano $\mathrm{TiO}_{2}$ Photocatalytic Paper for Removal of VOC Pollutants under Visible Light. Ind. Eng. Chem. Res. 2013, 52, 10961-10968. [CrossRef]

183. Sboui, M.; Bouattour, S.; Gruttadauria, M.; Marcì, G.; Liotta, L.F.; Boufi, S. Paper Functionalized with $\mathrm{Nanostructured} \mathrm{TiO}_{2} / \mathrm{AgBr}$ Photocatalytic Degradation of 2-Propanol under Solar Light Irradiation and Antibacterial Activity. Nanomaterials 2020, 10, 470. [CrossRef]

184. Barka, N.; Qourzal, S.; Assabbane, A.; Nounah, A.; Ait-Ichou, Y. Factors influencing the photocatalytic degradation of Rhodamine B by $\mathrm{TiO}_{2}$-coated non-woven paper. J. Photochem. Photobiol. A Chem. 2008, 195, 346-351. [CrossRef]

185. Rehim, M.H.A.; El-Samahy, M.A.; Badawy, A.A.; Mohram, M.E. Photocatalytic activity and antimicrobial properties of paper sheets modified with $\mathrm{TiO}_{2}$ /Sodium alginate nanocomposites. Carbohydr. Polym. 2016, 148, 194-199. [CrossRef]

186. Jiao, Y.; Wan, C.; Li, J. Anatase $\mathrm{TiO}_{2}$ /cellulose hybrid paper: Synthesis, characterizations, and photocatalytic activity for degradation of indigo carmine dye. Funct. Mater. Lett. 2017, 10, 1750018. [CrossRef]

187. Toro, R.; Diab, M.; De caro, T.; Kamar, M.; Adel, A.; Caschera, D. Study of the Effect of Titanium Dioxide Hydrosol on the Photocatalytic and Mechanical Properties of Paper Sheets. Materials 2020, 13, 1326. [CrossRef]

188. Ko, S.; Fleming, P.D.; Joyce, M.; Ari-Gur, P. High performance nano-titania photocatalytic paper composite. Part II: Preparation and characterization of natural zeolite-based nano-titania composite sheets and study of their photocatalytic activity. Mater. Sci. Eng. B 2009, 164, 135-139. [CrossRef]

189. Ko, S.; Pekarovic, J.; Fleming, P.D.; Ari-Gur, P. High performance nano-titania photocatalytic paper composite. Part I: Experimental design study for $\mathrm{TiO}_{2}$ composite sheet using a natural zeolite microparticle system and its photocatalytic property. Mater. Sci. Eng. B 2010, 166, 127-131. [CrossRef]

190. Adjimi, S.; Sergent, N.; Roux, J.C.; Delpech, F.; Pera-Titus, M.; Chhor, K.; Kanaev, A.; Thivel, P.X. Photocatalytic paper based on sol-gel titania nanoparticles immobilized on porous silica for VOC abatement. Appl. Catal. B Environ. 2014, 154-155, 123-133. [CrossRef]

191. Zhang, X.; Lu, X.; Shen, Y.; Han, J.; Yuan, L.; Gong, L.; Xu, Z.; Bai, X.; Wei, M.; Tong, Y.; et al. Three-dimensional WO $\mathrm{W}_{3}$ nanostructures on carbon paper: Photoelectrochemical property and visible light driven photocatalysis. Chem. Commun. 2011, 47, 5804-5806. [CrossRef] [PubMed]

192. Freire, T.; Fragoso, A.R.; Matias, M.; Pinto, J.V.; Marques, A.C.; Pimentel, A.; Barquinha, P.; Huertas, R.; Fortunato, E.; Martins, R.; et al. Enhanced solar photocatalysis of $\mathrm{TiO}_{2}$ nanoparticles and nanostructured thin films grown on paper. Nano Express 2021. [CrossRef]

193. Kansal, S.K.; Singh, M.; Sud, D. Studies on photodegradation of two commercial dyes in aqueous phase using different photocatalysts. J. Hazard. Mater. 2007, 141, 581-590. [CrossRef]

194. Coleman, V.A.; Jagadish, C. Chapter 1-Basic Properties and Applications of ZnO. In Zinc Oxide Bulk, Thin Films and Nanostructures; Jagadish, C., Pearton, S., Eds.; Elsevier Science Ltd.: Oxford, UK, 2006; pp. 1-20. [CrossRef]

195. Mohammad, V.; Umar, A.; Hahn, Y.-B. ZnO Nanoparticles: Growth, Properties, and Applications. In Metal Oxide Nanostructures and Their Applications; Umar, A., Hahn, Y., Eds.; American Scientific Publishers: Valencia, CA, USA, 2010 ; Volume 5, pp. 1-36.

196. Geurts, J. Crystal structure, chemical binding, and lattice properties. In Zinc Oxide; Springer: Berlin/Heidelberg, Germany, 2010; pp. $7-37$.

197. Wen, B.; Huang, Y.; Boland, J.J. Controllable Growth of ZnO Nanostructures by a Simple Solvothermal Process. J. Phys. Chem. C 2008, 112, 106-111. [CrossRef]

198. Alenezi, M.R.; Alshammari, A.S.; Jayawardena, K.D.G.I.; Beliatis, M.J.; Henley, S.J.; Silva, S.R.P. Role of the Exposed Polar Facets in the Performance of Thermally and UV Activated ZnO Nanostructured Gas Sensors. J. Phys. Chem. C 2013, 117, 17850-17858. [CrossRef] [PubMed]

199. Tong, Y.; Liu, Y.; Dong, L.; Zhao, D.; Zhang, J.; Lu, Y.; Shen, D.; Fan, X. Growth of ZnO Nanostructures with Different Morphologies by Using Hydrothermal Technique. J. Phys. Chem. B 2006, 110, 20263-20267. [CrossRef] [PubMed]

200. Liu, Y.; Liu, H.; Zhang, Q.; Li, T. Adjusting the proportions of $\{0001\}$ facets and high-index facets of ZnO hexagonal prisms and their photocatalytic activity. RSC Adv. 2017, 7, 3515-3520. [CrossRef]

201. Lahiri, J.; Batzill, M. Surface Functionalization of ZnO Photocatalysts with Monolayer ZnS. J. Phys. Chem. C 2008, 112, 4304-4307. [CrossRef]

202. Zhu, L.; Li, H.; Liu, Z.; Xia, P.; Xie, Y.; Xiong, D. Synthesis of OD/3D CuO/ZnO Heterojunction with Enhanced Photocatalytic Activity. J. Phys. Chem. C 2018, 122, 9531-9539. [CrossRef]

203. Meskine, H.; Mulheran, P.A. Simulation of reconstructions of the polar ZnO\$(0001)\$ surfaces. Phys. Rev. B 2011, 84, 165430. [CrossRef]

204. Lv, Y.; Zhang, Z.; Yan, J.; Zhao, W.; Zhai, C.; Liu, J. Growth mechanism and photoluminescence property of hydrothermal oriented $\mathrm{ZnO}$ nanostructures evolving from nanorods to nanoplates. J. Alloys Compd. 2017, 718, 161-169. [CrossRef]

205. Manjula, Y.; Rakesh Kumar, R.; Swarup Raju, P.M.; Anil Kumar, G.; Venkatappa Rao, T.; Akshaykranth, A.; Supraja, P. Piezoelectric flexible nanogenerator based on $\mathrm{ZnO}$ nanosheet networks for mechanical energy harvesting. Chem. Phys. 2020, 533, 110699. [CrossRef] 
206. Saleh, S.M. ZnO nanospheres based simple hydrothermal route for photocatalytic degradation of azo dye. Spectrochim. Acta Part A Mol. Biomol. Spectrosc. 2019, 211, 141-147. [CrossRef]

207. Yang, J.; Lin, Y.; Meng, Y.; Liu, Y. A two-step route to synthesize highly oriented ZnO nanotube arrays. Ceram. Int. 2012, 38, 4555-4559. [CrossRef]

208. Zhao, C.; Chen, A.; Ji, X.; Zhu, Y.; Gui, X.; Huang, F.; Tang, Z. Growth of vertically aligned ZnO nanowire arrays on ZnO single crystals. Mater. Lett. 2015, 154, 40-43. [CrossRef]

209. Wahab, R.; Ansari, S.G.; Kim, Y.S.; Seo, H.K.; Kim, G.S.; Khang, G.; Shin, H.-S. Low temperature solution synthesis and characterization of ZnO nano-flowers. Mater. Res. Bull. 2007, 42, 1640-1648. [CrossRef]

210. Moharram, A.H.; Mansour, S.A.; Hussein, M.A.; Rashad, M. Direct Precipitation and Characterization of ZnO Nanoparticles. J. Nanomater. 2014, 2014, 716210. [CrossRef]

211. Znaidi, L. Sol-gel-deposited ZnO thin films: A review. Mater. Sci. Eng. B 2010, 174, 18-30. [CrossRef]

212. Hasnidawani, J.N.; Azlina, H.N.; Norita, H.; Bonnia, N.N.; Ratim, S.; Ali, E.S. Synthesis of ZnO Nanostructures Using Sol-Gel Method. Procedia Chem. 2016, 19, 211-216. [CrossRef]

213. Liu, B.; Zeng, H.C. Hydrothermal Synthesis of ZnO Nanorods in the Diameter Regime of 50 nm. J. Am. Chem. Soc. 2003, 125, 4430-4431. [CrossRef]

214. Gerbreders, V.; Krasovska, M.; Sledevskis, E.; Gerbreders, A.; Mihailova, I.; Tamanis, E.; Ogurcovs, A. Hydrothermal synthesis of $\mathrm{ZnO}$ nanostructures with controllable morphology change. CrystEngComm 2020, 22, 1346-1358. [CrossRef]

215. Hasanpoor, M.; Aliofkhazraei, M.; Delavari, H. Microwave-assisted Synthesis of Zinc Oxide Nanoparticles. Procedia Mater. Sci. 2015, 11, 320-325. [CrossRef]

216. Taunk, P.B.; Das, R.; Bisen, D.P.; Tamrakar, R.K.; Rathor, N. Synthesis and optical properties of chemical bath deposited ZnO thin film. Karbala Int. J. Mod. Sci. 2015, 1, 159-165. [CrossRef]

217. Blachowicz, T.; Ehrmann, A. Recent developments in electrospun ZnO nanofibers: A short review. J. Eng. Fibers Fabr. 2020, 15, 1558925019899682. [CrossRef]

218. Illy, B.N.; Cruickshank, A.C.; Schumann, S.; Da Campo, R.; Jones, T.S.; Heutz, S.; McLachlan, M.A.; McComb, D.W.; Riley, D.J.; Ryan, M.P. Electrodeposition of ZnO layers for photovoltaic applications: Controlling film thickness and orientation. J. Mater. Chem. 2011, 21, 12949-12957. [CrossRef]

219. Gao, W.; Li, Z. ZnO thin films produced by magnetron sputtering. Ceram. Int. 2004, 30, 1155-1159. [CrossRef]

220. Fortunato, E.M.C.; Barquinha, P.M.C.; Pimentel, A.C.M.B.G.; Gonçalves, A.M.F.; Marques, A.J.S.; Martins, R.F.P.; Pereira, L.M.N. Wide-bandgap high-mobility $\mathrm{ZnO}$ thin-film transistors produced at room temperature. Appl. Phys. Lett. 2004, 85, 2541-2543. [CrossRef]

221. Golshahi, S. P-type ZnO thin film deposited by spray pyrolysis technique: The effect of solution concentration. Thin Solid Film. 2009, 518, 1149-1152. [CrossRef]

222. Mishra, Y.K.; Modi, G.; Cretu, V.; Postica, V.; Lupan, O.; Reimer, T.; Paulowicz, I.; Hrkac, V.; Benecke, W.; Kienle, L.; et al. Direct Growth of Freestanding ZnO Tetrapod Networks for Multifunctional Applications in Photocatalysis, UV Photodetection, and Gas Sensing. ACS Appl. Mater. Interfaces 2015, 7, 14303-14316. [CrossRef]

223. Araújo, A.; Pimentel, A.; Oliveira, M.J.; Mendes, M.J.; Franco, R.; Fortunato, E.; Águas, H.; Martins, R. Direct growth of plasmonic nanorod forests on paper substrates for low-cost flexible 3D SERS platforms. Flex. Print. Electron. 2017, 2, 014001. [CrossRef]

224. Manekkathodi, A.; Lu, M.-Y.; Wang, C.W.; Chen, L.-J. Direct Growth of Aligned Zinc Oxide Nanorods on Paper Substrates for Low-Cost Flexible Electronics. Adv. Mater. 2010, 22, 4059-4063. [CrossRef] [PubMed]

225. Ghule, K.; Ghule, A.V.; Chen, B.-J.; Ling, Y.-C. Preparation and characterization of ZnO nanoparticles coated paper and its antibacterial activity study. Green Chem. 2006, 8, 1034-1041. [CrossRef]

226. Jia, M.; Zhang, X.; Weng, J.; Zhang, J.; Zhang, M. Protective coating of paper works: ZnO/cellulose nanocrystal composites and analytical characterization. J. Cult. Herit. 2019, 38, 64-74. [CrossRef]

227. Zhao, S.-W.; Guo, C.-R.; Hu, Y.-Z.; Guo, Y.-R.; Pan, Q.-J. The preparation and antibacterial activity of cellulose/ZnO composite: A review. Open Chem. 2018, 16, 9-20. [CrossRef]

228. Shao, D.; Sun, H.; Gao, J.; Xin, G.; Anthony Aguilar, M.; Yao, T.; Koratkar, N.; Lian, J.; Sawyer, S. Flexible, thorn-like ZnOmultiwalled carbon nanotube hybrid paper for efficient ultraviolet sensing and photocatalyst applications. Nanoscale 2014, 6, 13630-13636. [CrossRef] [PubMed]

229. Li, Y.; Wang, K.; Wu, J.; Gu, L.; Lu, Z.; Wang, X.; Cao, X. Synthesis of highly permeable $\mathrm{Fe}_{2} \mathrm{O}_{3} / \mathrm{ZnO}$ hollow spheres for printable photocatalysis. RSC Adv. 2015, 5, 88277-88286. [CrossRef]

230. Chen, H.; Liu, W. Cellulose-based photocatalytic paper with $\mathrm{Ag}_{2} \mathrm{O}$ nanoparticles loaded on graphite fibers. J. Bioresour. Bioprod. 2016, 1, 192-198.

231. Hua, C.; Liu, X.; Ren, S.; Zhang, C.; Liu, W. Preparation of visible light-responsive photocatalytic paper containing $\mathrm{BiVO}_{4} @$ diatomite/MCC/PVBCFs for degradation of organic pollutants. Ecotoxicol. Environ. Saf. 2020, 202, 110897. [CrossRef] [PubMed]

232. ISO10678:2010. Fine Ceramics (Advanced Ceramics, Advanced Technical Ceramics)—Determination of Photocatalytic Activity of Surfaces in an Aqueous Medium by Degradation of Methylene Blue. Available online: https://www.iso.org/standard/46019.html (accessed on 20 February 2021). 
233. Shi, Z.; Zang, S.; Jiang, F.; Huang, L.; Lu, D.; Ma, Y.; Yang, G. In situ nano-assembly of bacterial cellulose-polyaniline composites. RSC Adv. 2012, 2, 1040-1046. [CrossRef]

234. Saito, Y.; Kamitakahara, H.; Takano, T. Preparation of a squaraine-bounded cellulose derivative for photocurrent generation system. Carbohydr. Res. 2016, 421, 40-45. [CrossRef] 